Florida International University FIU Digital Commons

\title{
The Development of a Qualitative Extension of the Identity Dimensions of Emerging Adulthood (IDEA) Measure Using Relational Data Analysis (RDA)
}

Shannon M. Quintana

Florida International University, quintans@fiu.edu

DOI: $10.25148 /$ etd.FI1 1080801

Follow this and additional works at: https://digitalcommons.fiu.edu/etd

\section{Recommended Citation}

Quintana, Shannon M., "The Development of a Qualitative Extension of the Identity Dimensions of Emerging Adulthood (IDEA) Measure Using Relational Data Analysis (RDA)" (2011). FIU Electronic Theses and Dissertations. 452.

https://digitalcommons.fiu.edu/etd/452 


\section{FLORIDA INTERNATIONAL UNIVERSITY \\ Miami, Florida}

THE DEVELOPMENT OF A QUALITATIVE EXTENSION OF THE IDENTITY DIMENSIONS OF EMERGING ADULTHOOD (IDEA) MEASURE USING RELATIONAL DATA ANALYSIS (RDA)

The thesis submitted in partial fulfillment of the requirements for the degree of MASTER OF SCIENCE

in

PSYCHOLOGY

by

Shannon M. Quintana

2011 


\section{To: Dean Kenneth Furton}

College of Arts and Sciences

This thesis, written by Shannon M. Quintana and entitled The Development of the Qualitative Extension for the Identity Dimensions of Emerging Adulthood (IDEA) Measure using Relational Data Analysis (RDA), having been approved in respect to style and intellectual content, is referred to you for judgment.

We have read this thesis and recommend that it be approved.

$\begin{array}{r}\text { Mary Levitt } \\ \hline \text { Wendy Silverman } \\ \hline \text { William M. Kurtines, Major Professor }\end{array}$

Date of Defense: July 22, 2011

The thesis of Shannon M. Quintana is approved.

Dean Kenneth Furton
College of Arts and Sciences

Florida International University, 2011 


\section{DEDICATION}

I dedicate this thesis to my mother, who taught me that anything is possible when you follow your dreams and focus on one step at a time. 


\section{ACKNOWLEDGMENTS}

I would like to thank the many people who have helped me throughout this

process. I would like to thank the entire YDP lab for their assistance, guidance, and motivation in completing this project, especially to Dr. Kurtines for his continual support and encouragement. And to my husband, I want to thank you for your loving support, understanding, and patience because, without you, this project would not have been possible. 


\author{
ABSTRACT OF THE THESIS \\ THE DEVELOPMENT OF A QUALITATIVE EXTENSION OF THE \\ IDENTITY DIMENSIONS OF EMERGING ADULTHOOD (IDEA) MEASURE \\ USING RELATIONAL DATA ANALYSIS (RDA) \\ by
}

Shannon M. Quintana

Florida International University, 2011

Miami, Florida

Professor William M. Kurtines, Major Professor

The current study was undertaken as a preliminary evaluation of a qualitative extension measure for use with emerging adults. A series of studies have been previously conducted to provide evidence for the reliability and validity of the RDA framework in evaluating youth development programs (Kurtines et al., 2008) and this study furthers this research to utilize RDA with emerging adults. Building on previous RDA research, the current study analyzed psychometric properties of the Identity Dimensions of Emerging Adulthood-Qualitative Extension (IDEA-QE) using RDA.

Inter-coder percent agreement among the Theoretical Open Coders (TOC) and Theoretical Content Coders (TCC) for each of the category levels was moderate to high, ranging from .67 to .87 . The Fleiss' kappa across all category levels was from moderate agreement to almost perfect agreement, ranging from .60 to .88 . The correlation between the TOC and the TCC demonstrated medium to high correlation, ranging from $r(31)=.65$, $\mathrm{p}<.001$ to $r(31)=.74, \mathrm{p}<.001$. 


\section{TABLE OF CONTENTS}

CHAPTER

PAGE

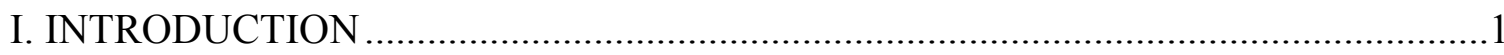

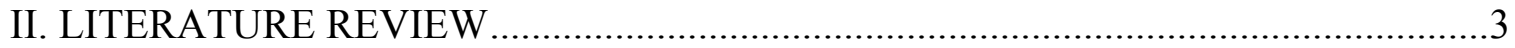

Emerging Adulthood as a Developmental Stage ...............................................4

Emerging Adulthood from a Life Span Development Perspective .........................5

What is Emerging Adulthood?..........................................................................

Identity Development in Emerging Adulthood................................................ 9

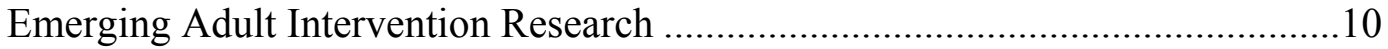

The Adult Development Project (ADP) ............................................................ 12

The Need for Relational Methods ....................................................................... 14

The Qualitative Extension (QE) Methodology ...............................................17

Relational Data Analysis.......................................................................... 18

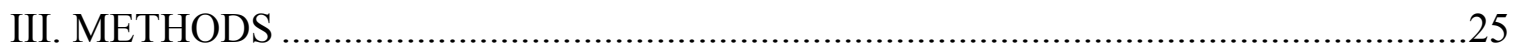

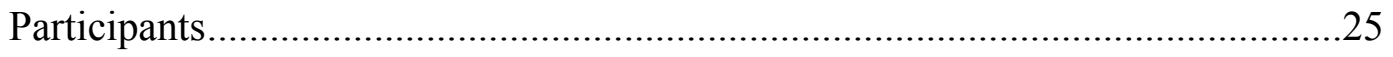

Recruitment of Participants........................................................................25

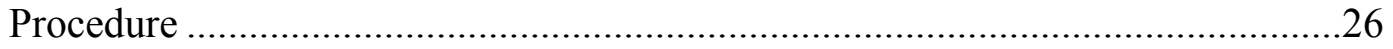

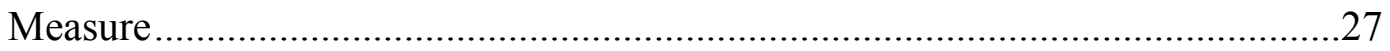

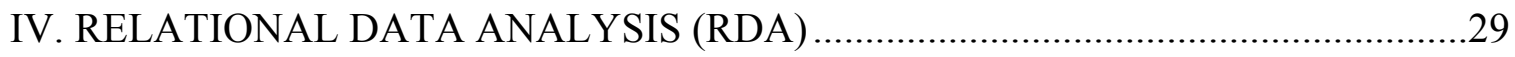

Conceptual Analyses: Conceptual Open Coding (COC) ......................................29

Theoretical Analyses: Theoretical Open Coding (TOC) ......................................30

Research Analyses: Theoretical Classification Coding (TCC) ............................32

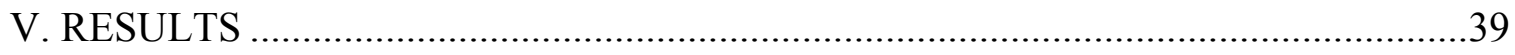

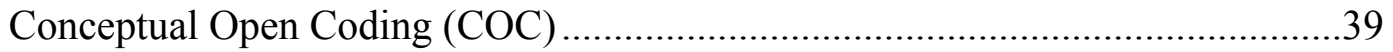

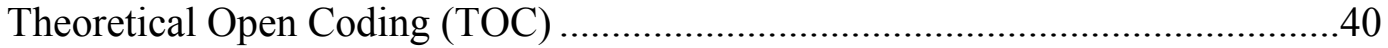

Theoretical Classification Coding (TCC) …............................................... 48

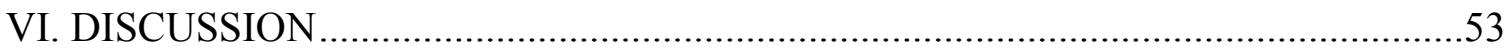

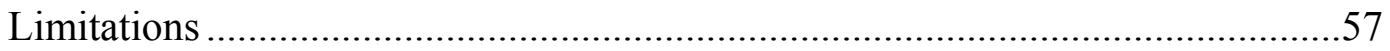

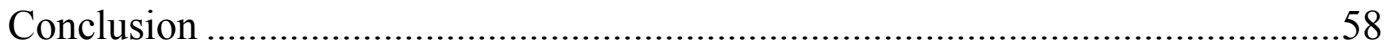

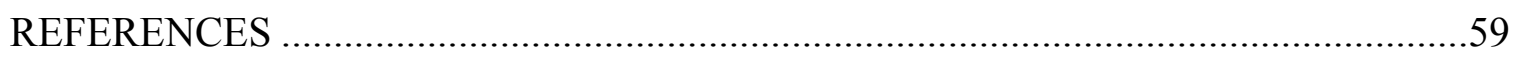

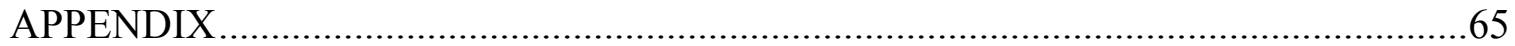




\section{INTRODUCTION}

Following the publication of Arnett's pivotal paper (2000) on emerging adulthood, research on this proposed developmental stage has grown considerably. Arnett (2000) proposed emerging adulthood (EA) as a new theoretically and empirically distinct developmental period between late adolescence and adulthood. As a newly-identified (and contested) developmental stage, research on emerging adults has primarily focused on enhancing the understanding of this period of life. A conceptual framework for EA has been proposed, in particular regarding identity development, and this conceptual framework has been used to establish a quantitative measure of emerging adulthood; however, there is a need to create a qualitative free response measure to comprehensively understand this new developmental stage.

In order to address this need, the current study supplements quantitative measures of core developmental constructs of emerging adulthood. The qualitative extension method (QE), whose goal is "identifying free response qualitative categorical linguistic properties evaluated by existing fixed response quantitative measures" (Rinaldi et al., under review, p. 3). The QE method uses a relational data analysis (RDA) approach. Relational Data Analysis is a multi-dimensional, multi-phasic framework for unifying the use of data analytic strategies across dimensions (quantitative/qualitative, causal/structural, etc.) and phases (conceptual, theoretical, and research analyses) (Kurtines et al., 2008). A series of studies have been previously conducted to provide initial evidence for the reliability and validity of the RDA framework in evaluating the Changing Lives Program (CLP) (Lewis Arango et al., 2008; Kortsch et al., 2008; Ritchie, 
2007; Rinaldi, 2008). These studies have indicated good reliability and validity for the RDA process for evaluating the Changing Lives Program.

This study will further evaluate the utility and reliability of utilizing RDA, specifically for use with emerging adults. The aim of the study is to enhance the growth of qualitative measures of developmental constructs of emerging adulthood using the qualitative extension (QEM) method from an RDA approach. Specifically, the aim is to develop a free response qualitative measure that extends and supplements dimensional properties of already existing quantitative measures.

The current study extends previous research in three distinct ways. First, the study's sample is primarily Hispanic, which supplements current emerging adult research that focuses on White Non-Hispanic emerging adults. Second, it answers Arnett's (2006) call for qualitative research on emerging adulthood. Arnett (2006) stressed the need and necessity of qualitative research for this population and this study's development of a qualitative extension measure does just that. Third, this study extends the use of RDA to emerging adults. Previously, RDA has been utilized with the CLP for use with at-risk adolescents. The current study, however, utilizes RDA for use with an emerging adult population at an urban university. 


\section{LITERATURE REVIEW}

Following the publication of Arnett's pivotal paper (2000) on emerging adulthood, research on the proposed developmental stage of emerging adulthood has grown considerably during the last decade. Arnett (2000) proposed emerging adulthood (EA) as a new developmental period between late adolescence and adulthood that is theoretically and empirically distinct. Several key features of this developmental period include identity exploration, unpredictability, and an age of possibilities (Arnett, 2004; Dwyer \& Wyn, 2001; Furlong \& Cartmel, 1997; Karlin \& Borofsky, 2003; Robbins \& Wilner, 2001).

As a newly-identified (and contested) developmental stage, research on emerging adults has primarily focused on enhancing the understanding of this period of life (Arnett. 2006). There is no consensus on the exact age parameters of this developmental stage, but the majority of researchers believe it occurs between the ages of 18 to 30 for most individuals, though some take larger to complete this stage of life until their mid-thirties (Arnett, 2004). A conceptual framework for EA has been proposed in particular regarding the process and sequencing of identity development during emerging adulthood (i.e., a three phase recentering process, cf. Tanner, 2006); however, there is a need to utilize this information to create real-world applications and interventions that integrate existing theory with qualitative and quantitative research (Arnett, 2006). In addition, there is a need to develop measures to examine developmental processes during this stage (2006). The purpose of this study is to develop a qualitative extension for the recently- 
created Identity Dimensions of Emerging Adulthood (IDEA) measure known as Identity Dimensions of Emerging Adulthood-Qualitative Extension (IDEA-QE) measure.

\section{Emerging Adulthood as a Developmental Stage}

The seemingly prolonged transition to adulthood has become a highly discussed topic in both popular media (Marantz Henig, 2010) and in the developmental literature. When Arnett (2000) proposed emerging adulthood as a new developmental stage, he provided evidence that this period was distinct demographically and in regards to identity formation. Arnett's (2000) emerging adulthood theory emerges from a developmental life-span perspective which focuses on "intra-individual change and stability, variation in individual's developmental trajectories, and influences that modify and optimize development across the human life span” (Tanner, 2006, p. 21).

Earlier theorists proposed frameworks about development between adolescence and adulthood. Erikson (1968) argued that though identity formation is the central issue in adolescence, there is a "prolonged adolescence" in industrialized nations where a psychosocial moratorium is provided. Emerging adulthood is a time "during which the young adult through free role experimentation may find a niche in some section of society" (p. 150). In 1970, Keniston also acknowledged the existence of a period between adolescence and adulthood and called it "youth." His theory was derived from examination of the population of protesting college students during the Vietnam era and it was reflective of the historical time more than on characteristics of a developmental stage. The current theory of EA, with Arnett $(1998,2000,2004)$ at the forefront, addresses the demographic changes that have created characteristics of this period of life. 
Contention about emerging adulthood centers on the idea that it is a distinct developmental stage. Arnett has argued that this stage exists only within a cultural context that allows for the prolonged exploration of roles and identity. Industrialized nations, in particular the United States, foster socialization practices (Arnett, 1995; Arnett \& Taber, 1994; Cote, 2000) that, combined with demographical shifts in recent years, promote a preparatory stage prior to adulthood (Arnett, 2004). In other words, they provide a lengthened period to discover who you are and what you want to do with your life (Arnett, 2000). Socialization practices which foster EA include the high rate of participation in higher education, delayed marriage, and later parenthood (Arnett, 2004).

Though there seems to be some consensus that there have been dynamic changes in 18-30 year olds in the past 50 years, some psychologists argue that criteria necessary for a new developmental stage are lacking. For example, Lerner questions the universality of EA, saying "The core idea of classical stage theory is that all people underscore 'all' — pass through a series of qualitatively different periods in an invariant and universal sequence in stages that can't be skipped or reordered" (qtd. in Marantz Henig, 2010, p. MM28). On the other hand, proponents of EA as a developmental stage argue that it is unique from other stages (adolescence and adulthood) and can be linked to these periods that occur before and after it (Tanner, 2006).

Emerging Adulthood from a Life Span Development Perspective

Emerging adulthood has also been considered using a life span developmental perspective. For example, Tanner (2006) argues emerging adulthood is not only a stage, but is also a critical turning point in lifespan human development. Experiences during EA 
impact the rest of the life course and are even recalled as important more so than any other time in the life course (Grob, Krings, \& Bagerter, 2001). Tanner (2006) proposes that the process that is underlying this stage is what she terms recentering. "Recentering constitutes a shift in power, agency, responsibility, and dependence between emerging adults and their social contexts - primarily experienced by emerging adults as a period during which parent regulation is replaced with self-regulation" (2006, p. 27). This recentering process is similar to the separation-individuation process that occurs since birth and continues throughout the lifespan. The difference is that recentering is relational and embedded within a dynamic systems framework, emphasizing "the relational, the give and take, between the emerging adult and his or her contexts" (p. 34).

The recentering process, according to Tanner (2006) consists of three stages. In Stage 1, which occurs at the beginning of emerging adulthood, the individual is embedded entirely within the family-of-origin. At this age, individuals gain legal responsibility for themselves, are required to account for their behavior, and are beginning to navigate the world on their own. During Stage 2, which is emerging adulthood proper, individuals explore their identities and choices. Contextual structures (e.g., family and school) are removed. Education, work, and relationships are exploratory and transitory. The temporary nature of these roles causes instability. For example, there is often multiple job changes, changes in majors, and intimate relationships come and go. Family-of-origin ties and parent-child relations are altered. They still often rely on family-of-origin for financial and other support, but are not required to heed their advice and can make their own decisions. In the final stage, Stage 3 , the individual is 
moving towards adulthood. Commitments and adult roles are established, which more clearly delineates the relationship between themselves and their family-of-origin. The “instability of emerging adulthood" (2006, p. 30) is transformed into the "stability underlying the momentum of adulthood" (p. 30).

Overall, the recentering process focuses on the change in the relationship between the individual and society. The dependence characteristic of adolescence gives way to the independence of adulthood and the responsibilities and commitments that come along with it. Tanner (2006) argues and provides empirical support (Helson \& Roberts, 1994; Henninghausen, Hauser, Billings, Schultz, \& Allen, 2004; Lasser \& Snarey, 1989; Schultz \& Selman, 1998) that the successful navigation of the recentering process is reliant upon ego development. Because there has been little research on the specific mechanisms that impact this transition, further study is necessary.

What is Emerging Adulthood?

Several key features of emerging adulthood have been described and center on the recentering that occurs during this period. Drawing on qualitative data from his multiple representative samples, Arnett $(2000,2004,2006)$ reported identifying five characteristics of emerging adulthood: an age of identity exploration; an age of instability; self-focused age; an age of feeling in-between; and, an age of possibilities (Arnett, 2004). The most significant of these characteristics, according to Arnett, is identity exploration. In EA, individuals explore who they are and what they want to be in life. The role of identity formation in EA will be discussed further in a later section of this paper. 
Emerging adulthood is a time of feeling in-between adolescence and adulthood. The structure and limitations of adolescence (i.e., parental rules, school, and "minor" status) gives way to more freedom and choices. However, at this stage, most young people do not consider themselves adults and have not taken on all adult responsibilities (i.e., a full-time job, marriage, and parenthood). In both qualitative and quantitative studies, three criteria for adulthood have been found with emerging adults: accepting responsibility for yourself; making independent decisions; and, becoming financially independent (Arnett, 1994; 1997; 1998; 2001; 2003; Nelson, 2003). Over time, emerging adults take on more responsibility, are confident in making their own decisions, and are financially independent. These changes occur gradually and incrementally and lead emerging adults to adulthood (Arnett, 2004).

Another characteristic of EA is that it is an age of possibilities. With the decrease in structure and increase in freedom, there are endless possibilities for emerging adult's futures. Emerging adults are able to make their own choices and independent decisions on work, school, and relationships. There is a wide array of options for careers and life paths and a sense that all hopes and dreams are possible (Arnett, 2004). However, the plethora of choices lends EA to be a period of instability. Emerging adults create a "Plan" (2004, p. 10-11) for their life that is constantly being altered. For example, they change majors in college multiple times over the four years, have many romantic relationships, and hold various jobs. A prime example of EA as an age of instability is that emerging adults move often during this period. They move out (and sometimes back in) with parents, live on college campuses in dorms, or move in apartments with friends 
or romantic partners. Emerging adults are exploring love, work, and relationships which makes this a time of instability and exploration, two things that go together (2004).

Finally, EA is the most self-focused time of life. Emerging adults do not have adult commitments and obligations (or minimal adult commitments) but do have the freedom to make their own choices. However, they are not selfish. Emerging adults move beyond the self-orientation and geocentricism that defined adolescence and plan on making adult commitments soon. Using the term self-focused, Arnett argues, is not derogatory, but "is normal, healthy, and temporary (Arnett, 2007). By focusing on themselves, emerging adults develop skills for daily living, gain a better understanding of who they are and what they want from life, and begin to build a foundation for their adults lives" (Arnett, 2004, p. 13).

Identity Development in Emerging Adulthood

Identity formation begins in adolescence, but intensifies during emerging adulthood. During their explorations of life possibilities, emerging adults discover who they are and what they want to be, which is a clarification of their identity. Erikson (1968) designated identity versus role confusion as the primary crisis in adolescence and research on identity has focused on this period. However, exploration during adolescence is tentative, transitive, and unfocused. Blos (1962) argued that adolescence is defined by explorations and it is in postadolescence (emerging adulthood) that identity consolidation occurs.

In terms of ego development...the psychic structure has acquired by the end of late adolescence a fixity which allows the postadolescent to turn to the problem of 
harmonizing the component parts of personality... This integration comes about gradually...The integration goes hand in hand with the activation of social role, with courtships, marriage, and parenthood (1962, p. 149).

Therefore, identity achievement is rarely reached before the end of adolescence (Arnett, 2004). A cross-sectional study found that ego identity status was not achieved until at least the age of 21 (Meilman, 1979) and one third of college graduates (ages 2124) still have identity issues (Cote \& Roberts, 2003).

During emerging adulthood, identity exploration and formation is more concrete than identity explorations of adolescents. Erikson (1968) himself posited a "psychosocial moratorium" (Erikson, 1968) after adolescence "during which the young adult, through free role experimentation may find a niche in some section of his society" (p. 150). This identity exploration process has been operationalized in various ways (see Schwartz, 2001 for a review), but has mainly been seen occurring during the period of life between adolescence and adulthood, namely emerging adulthood (Schwartz, Cote, \& Arnett, 2005). Because identity development has been linked to a multitude of positive outcomes, it is imperative to research methods of facilitating and fostering its growth.

\section{Emerging Adult Intervention Research}

In the growing field of emerging adulthood research, there is a need to emphasize intervention work (Arnett, 2006; Schwartz, Kurtines, \& Montgomery, 2005), specifically in regards to identity formation. Emerging adults encounter a plethora of opportunities and possibilities. This is especially true for college students who are exposed to a rich university environment (Cote \& Levine, 1997, 2000). For some emerging adults, the 
wide array of opportunities can be overwhelming without the proper support and may struggle in the identity-formation process that is integral to this time of life (Cote \& Allahar, 1994). The possibility of becoming overwhelmed is higher for minority and immigrant emerging adults who cultural values, norms, and expectations may differ from the majority culture (Arnett, 2000; Arnett \& Taber, 1994).

Individuals who are overwhelmed with the possibilities during this time of life would thus benefit from inventions that assist in identifying and selecting identity alternatives that help in forming an integrated sense of self (Archer, 1994). Indeed, there has been a growing body of literature on promoting identity formation; however, the majority of this research has focused on adolescents in adolescents (Enright, Ganiere, Buss, Lapsley, \& Olson, 1983; Ferrer-Wreder, Montgomery, \& Lorente, 2003; Berman, Schwartz, Kurtines, \& Berman, 2001; Rinaldi, 2011; Eichas, 2010) and there has been a paucity of research on promoting positive adult identity development with emerging adults (Markstrom-Adams, Ascione, Braegger, \& Adams, 1993; Schwartz, Kurtines, \& Montgomery, 2005; Berman, Kennerly, \& Kennerly, 2008). Schwartz, Kurtines, and Montgomery (2005) conducted a quasi-experimental study that evaluated the impact of two intervention strategies (cognitive-focused and emotion-focused) in a sample of 90 emerging adult university students and found that cognitive-focused intervention strategies were most efficacious in affecting the self-constructive identity processes whereas emotion-focused strategies were most efficacious in affecting the self-discovery identity processes, concluding that identity interventions should include both types of strategies to target both processes. 
Until recently, there has not been any ongoing program of intervention that directly targets identity as an outcome variable with adults of any age (e.g., emerging, young, middle, or late). The Daytona Adult Identity Development Program (Berman, Kennerly, \& Kennerly, 2008) was established to address this need and targets identity as an outcome variable using co-participatory and transformative intervention strategies. The intensive, multi-session intervention occurs within a personal growth elective psychology course and is administered by counseling master's students as part of their credentialing training. In a feasibility study, Berman, Kennerly, \& Kennerly (2008) found that the intervention increased identity exploration and decreased identity distress as well as increased achieved identity statuses and decreased foreclosed identity statuses. However, these effects as well as possible mediators and moderators need to be further studied and replicated (2008).

The Adult Development Project (ADP)

The Miami Adult Development Project attempts to further expand emerging adult intervention research with the Changing Lives Program (CLP). The ADP occurs within elective psychology courses at an urban university. Unlike the Daytona Adult Identity Development Program (Berman, Kennerly, \& Kennerly, 2008), the ADP intervention is administered by students in the course who volunteer to receive additional training on group work and peer facilitation by the course instructor or a graduate student. Additionally, the unique ethnic composition of Miami provides a diverse sample of often-understudied populations, including Hispanics. Integrating cognitive and emotion-focused intervention strategies, the CLP is a 
psychosocial developmental life course intervention strategy currently used with at-risk youth in Miami-Dade alternative high schools. It draws from psychosocial developmental theory (Erikson, 1968) that "adopts a view of the transition to adulthood that begins with the onset of adolescence as the developmental period at which the individual is first confronted with the difficult challenge of choosing the goals, roles, and beliefs about the world that give life direction and purpose as well as coherence and integration" (Kurtines et al., 2008, p. 3) as well as life course theory (Elder, 1998) that "adopts an emphasis on how individuals construct their own life courses through the choices they make and actions they take within the constraints and opportunities of historical and social circumstances" (2008, p. 3).

The CLP uses a "participatory transformative approach" in its intervention theoretical framework to reach its goal of encouraging already-empowered individuals to think critically about themselves, which promotes a positive identity. It is participatory in that participants themselves solve their problems - neither group leaders nor group members solve their problems; more rather, group leaders and group members offer possibilities that encourage participants to work on their life goals. It is transformative (Friere, 1983) in that participants realize that they have the power to transform their lives and is accomplished through mastery experiences. The self-directed transformative activities promote empowerment. "While intentionally identifying problems and engaging in transformative activities to solve life's problems (changing the way things are for the better), participants become 'experts' and in the process become empowered" (Kurtines et al, 2008, p. 5). Empowerment allows for the participant "to see closer 
correspondence between their goals and a sense of how to achieve them, gain greater access to and control over resources and ... gain mastery over their lives" (Zimmerman, 1995, p. 583). Because emerging adults (particularly college students) are already empowered, the CLP attempts to encourage the students to utilize their empowered selves to critically examine their life goals, which promotes positive development. In other words, it seeks to encourage participants to think critically about themselves, who they are, and where they want to be in order to create a more positive identity.

The Need for Relational Methods

Relational Methods in Developmental Research

There is a long-standing tradition in developmental psychology to place emphasis on quantitative research (Overton, 2006). Relational methods are important for developmental intervention science research because they expand the scope of inquiry. The scope of research is expanded beyond the examination of properties considered theoretically meaningful prior to conducting the research, which is often the case with cross sectional as well as longitudinal research (Eichas, 2010). In addition, the singular use of quantitative methods is limiting. Fixed response measures do not allow for the possibility of detecting response properties that are uniquely meaningful (ordinary language meaning, theoretical meaning, or both) within a specific population at a given time (Eichas, 2010).

Relational methods, such as Relational Data Analysis (RDA), which will be described further in a later section, provide a method which detects, identifies, and renders explicit and intelligible previously undetected or newly emergent properties that 
are impossible to find with traditional cross sectional or longitudinal research designs that only utilize quantitative methods (2010). The RDA process of detecting, isolating, identifying, and rendering explicit newly emergent categories occurs across the conceptual and theoretical phases. During the conceptual analysis phase of RDA, theory neutral coders are used in order to ensure that any longitudinally newly emergent content properties are identified using their ordinary language meaning (Kurtines et al., 2008). The lack of a formal theoretical orientation among the theory neutral ordinary language coders (who are also blind to time) and the exploratory, rather than confirmatory, nature of their task are designed to generate newly emergent content properties, facilitate the process of detecting, isolating, identifying, and rendering explicit response content properties, at least in terms of ordinary language meaning sense (Eichas, 2010). Moreover, RDA's explicit requirement for consensual agreement among the independent coders greatly limits the incorporation of the coder's own personal meanings as well as ensuring that particular content properties that lack consensual ordinary language meaning are not included in the analysis (2010).

During the theoretical analysis phase of RDA, the use of a panel of theoretically committed coders (who are blind to time) and the confirmatory (rather than explanatory) nature of their task make the detection of newly emergent content properties, that are theoretically meaningful from a specific theoretical framework, is also relatively straightforward (2010). In addition to their usefulness in describing previously identified content categories theoretically identifiable, theory laden coders are also useful in generating a theoretically meaningful developmental hierarchical structural organization 
model of the properties of the narrative expressions of the meaning and significance of participants' life course experiences.

\section{Relational Methods in Emerging Adult Research}

As is the case with developmental research, research on emerging adulthood favors quantitative research. The reliance on quantitative methods for emerging adult research is problematic and there are a number of reasons why qualitative research is necessary and appropriate with emerging adults. Because emerging adulthood is a new area of research and little is known about this life stage (Arnett, 2006), the use of qualitative work allows for unexpected responses and expands the scope of research beyond preexisting theoretical frameworks (Briggs, 1989). Using a relational approach, such as RDA, extends the scope of research to include properties and categories that were not defined prior to the research being conducted (Eichas, 2010). In addition, freeresponse research with emerging adults is especially important because this age demographic includes individuals who are highly capable of self-cognition, and have a great deal of insightfulness into their own lives that cannot be captured with fixedresponse quantitative research. Arnett (2006) argues that this self-reflection is indicative of this demographic and should be exploited. "Perhaps because emerging adulthood is the self-focused age, when people spend more time alone and are intently focused on issues such as what to do with their lives, emerging adults tend to be self reflective no matter what their backgrounds" (2006, p. 327).

Another benefit to qualitative research on emerging adults is that it can better reflect the heterogeneity of the emerging adult population. Emerging adulthood has a 
great deal of variability of experiences and does not have one normative trajectory that can best be captured with free-response data. Because of the benefits of the relational approach of RDA that were previously described, utilizing the RDA approach when conducting research on emerging adults is appropriate and beneficial.

The Qualitative Extension (QE) Methodology

Collection and analysis of qualitative data can be tedious and complex. The qualitative extension $(\mathrm{QE})$ methodology was established to address the complexity of procuring and analyzing qualitative data as well as to integrate such data with quantitative measures. The $\mathrm{QE}$ methodology was created to provide a procedure for creating free response qualitative extensions for concepts and constructs assessed by quantitative measures currently used in developmental research. The QE method provides a framework for creating qualitative extensions that collect the fullest, most comprehensive range of participant generated open-ended content. To do this, a standardized set of meaning and significance questions (i.e., what does this mean to you, how significant or important is this to you) with probes give a ready-at-hand-method for supplementing quantitative batteries with free response measures, which allows free response data that elicits access to the subjective meaning and significance of the content of the theoretical constructs of any given quantitative measure (Rinaldi et al., under review). A strictly quantitative approach cannot capture the subjective variation and variability in meaning and significance as a free response approach can. In addition, the QE methodology employs a relational approach, expanding the scope of research beyond what the examination of what is considered theoretically meaningful prior to conducting 
the research (Eichas et al., 2010). This subjective variation is analyzed using Relational Data Analysis (RDA).

\section{Relational Data Analysis}

The RDA Methodology

Relational Data Analysis is a multi-dimensional, multi-phasic framework for unifying the use of data analytic strategies across dimensions (quantitative/qualitative, causal/structural, etc.) and phases (conceptual, theoretical, and research analyses) (Kurtines et al., 2008). A comprehensive description of the RDA process will be provided in a later section of this paper. There are two primary research aims of adopting an RDA framework. First, RDA allows for patterns of differential positive qualitative (structural organizational) change in the subjective meaning and significance of participant life course experiences in general and also of their experiences of self and identity. Secondly, RDA provides the opportunity to identify the positive and problematic quantitative (dimensional) changes that predict, underlie, and/or accompany structural organizational change (Eichas, 2010). Relational Data Analysis attempts to overcome the splits (i.e., quantitative-qualitative) that have historically characterized developmental methodologies (Overton, 2006, Kurtines et al., 2008) by viewing quantitative (causal) variational change and qualitative (structural organizational) transformational change as merely two sides of a unified explanation.

Within the RDA framework, objective reports are seen as "raw" behavioral observations, as opposed to be viewed as definitive foundational data, that can be extended, refined, enriched, and verified by the data that is collected. Data collection 
occurs with measures and methods designed to capture as well as facilitate the interpretation of the human meaning and significance of the linguistic and culture-laden intentions of the person/people who are engaged in the observed behavior.

Narrative/linguistic expressions of the meaning and significance of life course experiences are elicited with open-ended measures (Eichas, 2010). Although the subjective meaning and significance of the experiences are not directly observable and therefore unavailable for direct analysis, the narrative/linguistic expressions of the subjective meaning and significance are available for inter-subjective examination and analysis (Montgomery et al., 2008).

In RDA, the collection of free response data and the intentional manipulation of the level of theoretical saturation of the coders (theory-neutral versus theory-laden) across phases of analysis are specifically designed to facilitate the detection of sample specific unique content properties in cross sectional research or newly emergent properties in longitudinal research (Eichas, et al., 2010). The open-ended narrative response data are coded using grounded theory data analytic strategies (Strauss \& Corbin, 1998) during each of RDA's three analytic phases: Conceptual, Theoretical, and Research Analyses. Kurtines et al. (2008) reported that the use of an experimental manipulation of three sets of coders (theory neutral, theory laden, theory neutral) that each use a distinctively different variant of the method of constant comparison provides multiple independent perspectives on the participant's response data, which has proved particularly useful when used in conjunction with a systemic application of the grounded theory method of constant comparison. 
Reversibility and the Cyclical Nature of RDA

The RDA process is cyclical in nature. From an RDA perspective, movement through the three phases, Conceptual, Theoretical, and Research Analyses, is cyclical and open to diverse types of modifications (i.e., conceptual, theoretical, and/or empirical) in the process of completing each cycle. On the basis of empirical findings (or lack of findings), any and/or all of the medications are capable of transforming the movement of the next new cycle into a directional spiral (Kurtines et al., 2008).

It has been found that movement through the core cycle of RDA is usually reversible as well as cyclical, which is consistent with Overton's (2006) articulation of knowledge development as a directional spiral. That is, conceptual, theoretical, and empirical results/findings generate new iterations of analysis and/or recycling through previous analytic phases in a dialectical way (2006). For example, an RDA cycle that begins at the conceptual analysis phase may identify a set of categories, that during the theoretical analysis, may have contain enough theoretically meaningful and/or relevant information to identify plausible theoretical hypotheses about structural organizational patterns within or between identified categories about the causal relationship between identified variables. In this case, additional data of the same type or additional data of an alternative type may need to be collected and there would then be a return to the conceptual analysis phase to identify a new set of categories.

On the other hand, the open coding may identify a set of categories that show to be theoretically meaningful and provide relevant information that generate plausible theoretical and/or research hypotheses in the subsequent theoretical analysis phase. 
Completion of the open coding results in the movement to the next phase of the cycle, the research analysis phase. The hypothesis testing that occurs during this phase may fail to adequately support the research hypotheses, which requires a return to a previous conceptual or theoretical phase (or even back to data collection) to identify new categories and/or generate new theoretical and/or research hypotheses. Hierarchical Structural Organization of Properties: Flat and Nested Relationships In RDA, theory laden coders identify a theoretically meaningful hierarchical structure organization of the RDA root category and the associated subcategories. A structural tree chart is generated to visually represent the organizational structure of the root category and the associated subcategories that were identified in the data set as theoretically meaningful (Eichas, 2010). The coders use standard naming conventions in generating the structural tree chart. The structural tree chart is an organizational structure that is called a "tree" because it resembles an upside down tree with the roots on top and the leaves on the bottom. Each tree structure has an element at the top called the "root" or root node (Kurtines et al., 2008). The lines that connect the elements are called "branches", while the elements themselves are called "nodes." The nodes that are on top are called parents nodes and the ones below are called child nodes. Nodes that do not have children are called "end nodes" or "leaves."

Identification of theoretically meaningful hierarchical structural organizations for subcategories draws on dynamic developmental systems perspective (Lerner, 2002) in general, and on the application of constructs derived from hierarchy theory (Pumain, 2006) in particular. "Hierarchical systems" were defined by Pumain (2006) as those that 
have a number of elements that can be described at least three levels of observation (i.e., the system, the subsystem, and the elements). The structural organization can be depicted in multiple ways, including the number of subsystems that comprise the system, the number of elements that comprise the subsystems, and the number of properties of each element. In addition, it may be summarized by the statistical distributions within or across subsystems. The structural organization may also be characterized in terms of their structural arrangement (e.g., flat, nested, balanced, etc.).

Relational Data Analysis draws on this hierarchy theory (Pumain, 2006) specifically for characterizing the organization structure of the theoretically meaningful subcategories identified by theoretical coders as well as dynamic developmental systems theory (Lerner, 2002) for conceptualizing structural and organizational change over time. The standard systems theory hierarchical structural organization model is extended to include a fourth, non-hierarchical, non-structural, non-organizational component: a temporal component, which depicts change over time (represented by $\mathrm{T} 1 \rightarrow \mathrm{T} 2 \ldots$ ). The temporal component's focus is on a specific pattern of change and successive change over time that can be characterized as developmental in nature (i.e., developmental change; Rinaldi, 2011).

Research Using RDA

Several studies have been conducted that examine Relational Data Analysis. Specifically, research has extended and refined the use of RDA to evaluate the Changing Lives Program (CLP). Lewis Arango et al. (2008) and Kortsch et al. (2008) examined categories and subcategories of two measures. In these studies, during the Theoretical 
Analysis Phase, theoretical coders identified non-overlapping theoretical categories (some with associated sub-categories) of the Life Course Interview (LCI) and the Possible Selves Questionnaire (PSQ) respectively. A Theoretical Category Structural Tree Chart (STC) and accompanying set of property descriptions as the last step in the theoretical analysis phase were reported in both studies. Consistent with RDA procedures in use at the time, psychometric analysis of theoretical categories classified using the STC were conducted as the first set of tasks of RDA's Research Analysis phase.

Ritchie (2007) provided an extension of Relational Data Analysis. The activities of the Theoretical Analysis Phase of RDA included two additional tasks: the development of an RDA Coding Template (CT) in addition to the STC and psychometric analysis using the RDA CT instead of conducting a psychometric analysis using the Structural Tree Chart. Additionally, Ritchie (2007) transferred the psychometric analysis into the Theoretical Analysis Phase instead of including it in the Research Analysis Phase. In this study, the inter-coder agreement calculated using Pearson's correlation, among the three theory neutral coders for each of the specific categories was moderate to high, with a range of .89 to .99 . The Fleiss' kappa across all the categories was .68, providing evidence for a moderately high degree of construct validity for the categories.

In addition, Rinaldi (2008) paralleled the RDA procedures utilized by Lewis Arango et al., (2008) and Kortsch et al., (2008) and performed a complete RDA by including the extensions utilized in Ritchie (2007) in analyzing the psychometric properties of the Personally Expressive Activities Questionnaire-Qualitative Extension (PEAQ-QE). The current study further extended the RDA procedure to include 
developmental hierarchical structural organization of participants' most important life goals. 


\section{METHODS}

\section{Participants}

Participants are an urban gender inclusive, multi-cultural sample of emerging adult undergraduates. Criterion of participation in the study was that the student be at least 18 years of age because of consent issues and mandatory reporting concerns that arise when dealing with underage individuals. No other exclusion criteria were utilized.

The sample for this study contains 70 participants. There are 52 females and 18 males. Ages range from 20 to 34 with the average age 23.2 years and a standard deviation of 3.7 years. The ethnic composition of the sample is 63 Hispanic, 1 White Non-Hispanic, 2 African American, 3 Other, and 1 Bi-Ethnic.

\section{Recruitment of Participants}

Participants were recruited to participation through an elective psychology course. Students in the course were told about the study and asked to provide informed consent. At this time, the students were told that they must participate in the Changing Lives Program intervention groups and take the assessments twice during the semester as part of the curriculum for the course. Because the research study centers on key aspects of the curriculum of the course (research on emerging adulthood and interventions with emerging adults), all students were required to complete the assessments. The research study (the project manual, for instance) as well as the intervention itself (the CLP groups and accompanying Journal Exercises) were discussed at length in the lectures.

However, only the assessments of consenting individuals were analyzed. Data from students who did not consent to participation were deleted and not analyzed. The 
procedure and the rationale for completing the assessments were explained during the first week of the course.

\section{Procedure}

This study occurred within an elective psychology course about positive development and emerging adulthood. At the beginning of the semester, students were informed that a portion of the course's curriculum is the Changing Lives Program. In lieu of lecture, one class per week during the last six weeks of the semester were groups that went through the Changing Lives Program Life Course Journal exercises.

In addition, they will be informed that a completion of a battery of measures twice during the semester will count towards their final course grade. Students were asked to consent to the data from these measures being used as part of the Adult Development Project. The consent rate for the two semesters of date analyzed in this study was $85 \%$. The sample in this study included only these consenting participants and the data from the $15 \%$ non-consenting students were deleted.

The assessment measures were taken twice during the semester, once at the beginning of the semester and again at the end of the semester after the CLP groups. Measures were made on the secure online Florida International University Qualtrics system. Students were given directions on how to complete the measures in class and had one week to complete the measures after the assignment was given by the professor. The assessments were in no way related to the content of the Changing Lives Program groups and were not discussed during the group sessions. 


\section{Measure}

The Identity Dimensions of Emerging Adulthood-Qualitative Extension (IDEAQE) builds on the pioneering worth of Reifman, Arnett, and Colwell (2007) in the development of the Identity Dimensions of Emerging Adulthood (IDEA) and the literature on emerging adulthood (e.g., Arnett's theory of emerging adulthood). The IDEA measures identification with emerging adulthood themes described by Arnett (2004; 2006), including identity exploration, experimentation, negativity, other-focused, self-focused, and in-between using a Likert-like scale format. As part of the Adult Development Project (ADP), the IDEA is administered and scored as originally developed by Reifman, Arnett, and Colwell (2007).

After participants completed the standard IDEA ratings, the standard Qualitative Extension (QE) module for eliciting free response narrative data was completed. Because of this addition of free response probes the Identity Dimensions of Emerging AdulthoodQualitative Extension (IDEA-QE) extends the standard IDEA instrument by providing a method for eliciting participant's open-ended narrative descriptions of the subjective meaning and significance of the experiences of emerging adulthood, which are analyzed within the Relational Data Analytic framework.

Specifically, in the IDEA-QE, participants choose the most important two of these five characteristics for themselves. They are asked "Of the five features described above [Arnett's five features of EA are described], which two do you believe come closest to your experience of emerging adulthood?" Then, participants are asked about which is the most indicative for themselves. The question is "Of these two, which do you believe has 
been your most characteristic or important experience?" The measure also asks about the meaning and significance of emerging adulthood for the participant ("What does being an emerging adult mean to you?" and "How is it significant or important to you?"). For this study, only the participant's response to the meaning and significance questions were examined. The data from these responses were coded and analyzed using Relational Data Analysis (RDA). 


\section{RELATIONAL DATA ANALYSIS (RDA)}

A complete RDA encompasses all procedures utilized by Lewis Arango et al. (2008), Kortsch et al. (2008), and Ritchie (2007). Below is a brief description of these RDA procedures.

\section{Conceptual Analyses: Conceptual Open Coding (COC)}

During the Conceptual Analysis phase of RDA, a set of theoretically neutral conceptual coders (coders systematically selected to represent no particular theoretical perspective) are assembled to pursue the grounded theory concept of "open" coding as well as the method of constant comparison. The method of constant comparison (Strauss \& Corbin, 1998) is the process of comparing content properties of participant response data for similarities and differences that draws on an ordinary language perspective (Wittgenstein, 1953) and is operationalized as the comparison of the properties of participant response data for the purpose of creating and eliminating "ordinary language" content groups of responses with each group of responses defined by a single unique ordinary language content property. These ordinary language content properties that are identified in the raw response data are used to identify all qualitatively different (nonoverlapping) groups of responses in the data set, and to formulate and document an explicit description of the unique content property that the response data of each content group share in common (their similarity) and that they do not share with any other content response group (their differences; Kurtines et al., 2008). In other words, the theory neutral coders identify all of the unique content properties in a particular data set and thus break the data down into the largest possible set of basic elements, with each 
element representing the most basic conceptually meaningful unit of content from an ordinary language perspective (Eichas, 2010).

Theoretical Analyses: Theoretical Open Coding (TOC)

During the Theoretical Analysis phase of RDA, a set of theoretically committed coders (coders that are systematically selected to be representative of a particular theoretical perspective) are assembled to work collaboratively on four tasks, each of which has a particular type of outcome. Specifically, during this phase, the theoretical coders are asked to use the method of constant comparison to review and discuss the content categories identified in the previous conceptual phase, from the perspective of guiding theory.

Theoretical Analysis Task 1: Identifying Theoretical Categories

During Task 1, the task of the theoretical coders is to identify the root category and the smallest number of theoretically meaningful associated subcategories using a defined theoretical perspective. For this task, the coders use the initial pool of conceptual categories that were identified in the raw data by the theory neutral coders during the conceptual coders. In addition, the theoretically committed coders also generate a set of property descriptions of the unique properties that define each subcategory. As a part of this task, the theoretical coders are asked to formulate and document an explicit description of the unique property that the response data of each theoretical subcategory share in common (similarity) and that they do not share in common (difference; see Lewis-Arango, Kurtines, Montgomery, \& Ritchie, 2008; Kurtines et al., 2008). 
Theoretical Analysis Task 2: Identifying Relations

During Task 2, the task of the theoretically committed coders is to identify a theoretically hypothesized structural organization between the identified theoretical subcategories (e.g., flat, nested, hierarchical, etc.), from which a Structural Tree Chart (STC) is constructed. The STC is a visual representation of the structural organization among the root category, subcategories, and the identified properties (see Kurtines et al., 2008).

Theoretical Analysis Task 3: Identifying Mechanisms of Change

During Task 3 , the theoretically committed coders identified and specified hypothesized plausible mechanisms that provide a theoretically meaningful (and plausible) explanation of change over time (causal/functional, structural/transformational, etc.) in the theoretical subcategories. This third outcome is only generated when the theoretical analysis involves a temporal analysis of change (e.g., a developmental analysis, a historical analysis, etc.) (see Kurtines et al., 2008).

Theoretical Analysis Task 4: Constructing a Decision Tree Chart (DTC)

During Task 4, the unique properties that define each subcategory are translated into decision rule formats, and formulated rules are utilized to construct a Decision Tree Chart/ Decision Tree Matrix (DTC/DTM). The theoretical coders construct a DTC (and the associated DTM) that will be used for the classification coding of uncoded free response data into the subcategories that emerged out of the open coding process during the theoretical analysis phase. 


\section{Research Analyses: Theoretical Classification Coding (TCC)}

In RDA, the TCC is conducted as the last step in the RDA Theoretical Analysis Task 4 by theoretically neutral coders for use as part of the Theoretical Analysis Task 5 psychometric analyses. A new set of theoretically neutral coders is assembled to conduct the TCC task of RDA. Training the TCC coders is the same as the training of COC coders, with the appropriate modifications to the required tasks. The coders are provided with copies of the Sample Coding Cards that were used during the COC and TOC, the Coding Glossary, DTC, and the category descriptions developed during the TOC. The panel conducts the second coding procedure of the initial sample set using all of the provided information that was developed by theoretical coders during the TOC phase of Relational Data Analysis.

Theoretical Analysis Task 5: Psychometric Analyses: Reliability and Validity Analyses of an RDA Coding Template (RDA-CT)

The final task of the RDA Theoretical Analysis Phase is to conduct a three-step preliminary psychometric analysis, including reliability and validity estimates, of the DTC constructed in the previous phase, called a Psychometric Analysis of the Theoretical Classification Coding Decision Tree Chart (PA-DTC).

Theoretical Analysis Task 5, Step 1: Estimating inter-coder reliability. In the quantitative/experimental research traditions, reliability is the extent to which a measurement method is repeatable and yields consistent results. The most important outcome of the conceptual and theoretical analysis phases of RDA is the identification of conceptual and theoretical categories; therefore, an important psychometric property of 
identified coding categories is the consistency with which they can be used to accurately classify response data into theoretical categories (i.e., the reliability of the coding categories). To estimate inter-coder consistency of an RDA-CT, RDA standard psychometric analysis of coding templates used the inter-coder agreement percent among the coders for each category level to provide an estimate of inter-coder reliability for the TOC and TCC (Ritchie, 2007; Kurtines et al., 2008).

In addition, inter-coder agreement is estimated using Fleiss kappa. Fleiss' kappa incorporates a correction for chance agreement and allows for greater generalizability because it can be used to measure the significance of the agreement among multiple raters with the significance level being adjusted relative to the number of comparisons made. Cohen's kappa, on the other hand, only tests for the significance of two raters at a time (i.e., in pairs of ratings) (Fleiss, 1973). If the agreement is found to be high, it is assumed that the ratings do reflect the dimensions they are presumed to, whereas a low or 0 kappa indicated high measurement error (Fleiss, 1973). Specifically, agreement from 0 to .20 assumes slight agreement, .21 to .40 assumes fair agreement, .41 to .60 assumes moderate agreement, .61 to .80 showing substantial agreement and .81 to .99 assumes the almost perfect agreement.

Theoretical Analysis Task 5, Step 2: Estimating construct validity. In the quantitative/experimental research tradition, validity is said to be the extent to which a measurement method measures what it is supposed to measure. Construct validity was first introduced by Cronbach and Meehl (1955) to extend the two types of psychometric validity previously recognized, content and predictive validity. Since its inception, 
construct validity was recognized as the most important type of validity, as well as the most complex to indicate (Anastasia \& Urbina, 1997) and requires the accumulation of evidence that a measurement method is linked to the theoretical construct it is hypothesized to represent, which is a long and complex process which usually includes at least three basic types of evidence: criterion-related (including predictive and concurrent), convergent, and discriminant validity (Anastasia \& Urbina, 1997; Campbell \& Fiske, 1959; Nunally, 1978). Evidence that a method is a valid measure tends to be indirect in regards to construct validity.

In addition, the process of construct validation is never really finished and there is never a time where a measurement method can be declared valid. Construct validation is a process in which the degree of validity of a given measurement method for a particular theoretical construct is represented by the accumulated evidence regarding the multiple psychometric properties within the supporting concepts and constructs (i.e., the theory) that defines the theoretical construct (Campbell \& Fiske, 1959). The boundaries, therefore, between the validation of a measuring a theoretical construct and the validation of the theory that defines the theoretical construct become blurred, with the results often providing (or failing to provide) evidence in support of neither or both (Nunnally, 1978).

With this context in mind, inter-coder agreement across all of the categories in $\mathrm{RDA}$ is considered to move beyond the methodological issue of estimating the reliability of each of the categories identified by the emerging grounded theory to begin to address the theoretical issue of construct validity of the emerging grounded theory, i.e., the relations among the categories. In grounded theory, the content properties identified by 
the conceptual analysis are seen as defining the basic elements of emerging theory and the theoretical properties of the categories identified by the theoretical analysis as defining the basic concepts or constructs of the nomological network of the emerging theory. The second step of theory construction in RDA, as previously discussed, is the identification of the smallest number of qualitatively different, non-overlapping theoretically meaningful categories and an explicit description of the properties that define them in a specific data set.

Furthermore, the aim of grounded theory is to construct qualitatively theories with respect to the organization and relations among qualitatively different variables and the theoretical expectation is that in the process of constructing a theoretical structural organization of the categories, each of the identified categories will have a unique property. Confirmatory construct evidence for the validity of the emerging theory stems from evidence that each construct in the theory is unique and non-overlapping with every other category (construct), while evidence that each construct in the theory is not unique and not non-overlapping with every other category provides non-confirmatory evidence for the validity of the emerging theory. Thus, the inter-coder agreement for each category provides an estimate of the inter-coder reliability for that specific category and the average inter-coder agreement across all categories provides a global index of the goodness of fit between a theoretically hypothesized nomological network among the identified theoretical categories and the actual relation among them (Kurtines et al., 2008). 
For example, if the theoretical structure identified in the TOC is comprised of four categories, a high inter-rater agreement across all categories provides evidence for the construct validity of the hypothesized structural organization of the categories. The structural organization would include all the unique categories that make up the nomological network of the emerging theory. The nomological network constituted the theory within which each identified category is embedded and that the classification coders, whether implicitly or explicitly, use in generate in their comparative judgments when coding and classifying responses into categories. A high average inter-coder agreement across the categories means that the theoretical classification coders were able to classify each of the responses into its appropriate categories. The coder's decision to classify a specific response into a category involves a simultaneous judgment that the property that defines that particular response is the same property that the theoretical coders identified as defining the chosen category and that the property is different than those in other categories (Kurtines et al., 2008).

On the other hand, a moderate average inter-coder agreement across all of the categories means that the TCC coders were only partially able to accurately classify the responses into appropriate categories and provides moderate evidence for the construct validity of the hypothesized structural organization (Kurtines et al., 2008). Additionally, a low average inter-coder agreement across all categories means that the TCC coders were not able to classify accurately each of the responses into appropriate categories and provides evidence for the absence or lack of construct validity for the hypothesized structural organization (Kurtines et al., 2008). Finally, variable inter-coder agreement, 
meaning that some categories indicate high inter-coder agreement while others do not, indicate that the TCC were only able to classify some of the responses into appropriate categories and provides evidence for differential construct validity for a given subset of the hypothesized structural organization (Kurtines et al., 2008).

With variable inter-coder agreement, high inter-coder agreement for a category is interpreted as providing evidence that the category (and the associated nomological network to which it is linked) is theoretically meaningful and low inter-coder agreement for a category (and its nomological network) is theoretically meaningless (Kurtines et al., 2008). Therefore, the second step provides preliminary evidence (or lack of evidence) for the construct validity of a particular organization of the phenomena that is explained by the emerging theory.

Furthermore, in those cases where Task 1, Step 2 yields either consistently high or consistently low average inter-coder agreement across all categories, an examination of the results of the inter-coder agreement for each specific identified category in Task 1 , Step 1 will yield information redundant with the results of Task 1, Step 2. In other words, if the average inter-coder agreement across all categories are high (or low), intercoder agreement across all the specific categories will also be respectively either high (or low). However, if the average inter-coder agreement yields mid to moderate inter-coder agreement, the results provide a more useful index of goodness of fit in that an examination of the results of the inter-coder agreement for each specific identified category may yield significant theoretically and empirically useful information with respect to the relative construct validity of each specific identified category, which 
categories merit continuing on to the research analysis phase of the RDA, and which categories need to be returned to an earlier phase of the relational data analysis cycle to undergo further conceptual or theoretical analysis and refinement before moving to the research analysis phase (Kurtines et al., 2008).

Theoretical Analysis Task 5, Step 3 Estimating criterion-related (concurrent) validity. Criterion-related validity includes concurrent and predictive validity. Concurrent validity estimates the degree to which a measure relates to other manifestations of the same theoretical construct (e.g., the correlation between a measure of patients' self-reported depression symptoms and clinician ratings of depression symptoms in a treatment study). Predictive validity evaluates whether a measure relates to manifestations of other constructs the measurement method is theoretically hypothesized to predict.

In RDA, this step is to use the correlation between the identified categories of the theoretical coders and the theoretical category classifications generated by a second set of theory neutral conceptual coders to estimate the concurrent (external) validity of the categories. In this step, the resulting correlation coefficient is interpreted as a coefficient of concurrent validity (as a type of criterion-related validity) obtained using a variant of the widely recognized multitrait-multimethod matrix method first introduced by Campbell and Fiske (1959) (Ritchie, 2007, Kurtines, et al., 2008). 


\section{RESULTS}

The data analysis for the current study was comprised of the two RDA phases of analyses and the same three-step psychometric analysis (reliability and validity estimates) as described above. The following section reports the psychometric properties generated by the RDA for the Identity Dimensions of Emerging Adulthood-Qualitative Extension (IDEA-QE).

\section{Conceptual Open Coding (COC)}

Conceptual open coding was conducted on each of the participant's "raw" response data, called a Macro Interview Response (MIR). Macro Interview Responses consisted of all the words, phrases, and sentences a participant used to describe the meaning and significance of the experience (topic, issue, question, etc.) under investigation. The first task of the Conceptual Analysis Phases was to assemble the material used in the COC, which included creating MIR coding cards for all the response data. Then, a set of 31 "Sample Coding Cards" which were a theoretically representative set were selected from the larger sample under study. Finally, a set of five theoreticallyneutral conceptual coders were assembled to code the "Sample Coding Cards", using the grounded theory concept of "open" coding and the method of "constant comparison" for similarities and differences in the comparison of the properties of participant response data to identify unique content properties that define the basic pool of conceptual categories in the raw response data, use those properties to identify all qualitatively different (non-overlapping) conceptual categories in the data set, and formulate and document an explicit description of the unique content property that the response data of 
each conceptual category share in common (similarity) and what they do not share with any other category (difference) (Kurtines et al., 2008).

The theoretically-neutral coders were first given a brief orientation to RDA and the current study as well as a general explanation of the goals of coding (i.e., to identify and classify answers to questions into conceptually meaningful groups or categories) and an overview of the process that would be used (i.e., by sorting cards containing responses). Then, coders reviewed the sample set and identified a preliminary initial set of three non-overlapping conceptual categories (Exploring, Transitioning, and Responsibility) contained in the data set.

\section{Theoretical Open Coding (TOC)}

The initial set of conceptual categories identified during the COC provided the data for the theoretical analysis of this phase. A panel of five theoretical coders was assembled to review the entire IDEA-QE sample set (31 MIRs) for the three conceptual categories in order to gain an understanding of what the conceptual coders identified as the properties of the conceptual categories. The theoretically meaningful categories were discussed to consensus, as were the organizational structure (STC) of the categories and translated the unique properties of the categories into the DTC, and then performed an open coding session using the sample set.

Theoretical Analysis Task 1: Identifying Theoretical Categories

During this task, theory-laden coders utilized Arnett's and Tanner's theory of emerging adulthood as the primary theoretical perspective for this theoretical analysis. This theoretical coding is different from the content category coding because the COC is 
completed by coders with no theoretical perspective (or, more distinctly, coders with multiple variegated implicit theoretical perspectives). In the TOC, the open coding is completed by coders who explicitly share the same identified and extensively articulated theoretical perspective.

The first phase of the theoretical analysis was conducted with a panel of five theoretical coders, who were given the task of identifying theoretically relevant and meaningful categories contained in the pool of content categories identified during the COC by theory-neutral coders. The theoretical coders were provided the sample MIR coding cards that were grouped into the categories formulated during the $\mathrm{COC}$ as well as the descriptions for the categories and were asked to review the cards and content property descriptions in order to refine the basic content categories and the structure of the groupings generated by the content coders during the Conceptual Open Coding. In addition, they were asked to identify theoretically meaningful properties and organize them into groups (categories) and respective subcategories in ways that were meaningful to the theoretical framework (i.e., Arnett's emerging adulthood).

After these categories and subcategories were identified and their relationships described, the last step in finalizing the identification of the theoretical categories was the construction of a visual representation of the structural organization of the categories, called a Structural Tree Chart (STC). In RDA, the STC that are created in the TOC process provide a conceptual framework (e.g., a visual tool) for reporting the structural organizations and also facilitate the identification of theoretical categories during the open coding process (see Appendix A for the RDA CT used in this study). 
As visually presented in the Figure 1 Structural Tree Chart (STC), the theoretical analysis of the meaning and significance questions yielded two Level 1 categories (Exploring and Committed) each with three Level II subcategories. The subcategories of Exploring were, Independence, Self-Discovery and Mixed; the subcategories of Committed were Autonomy, Self-Directed and Mixed. The structural organization of these theoretical categories and subcategories and their property descriptions of the unique categories can be found in Appendix A.

Additionally, as previously described, RDA extends the standard system theory hierarchical structural organization model to include a fourth, non-hierarchical, nonstructural, non-organizational component: a temporal component, which depicts change over time (represented by $\mathrm{T} 1 \rightarrow \mathrm{T} 2 \ldots$ ), focusing on a specific pattern of change and successive change over time that can be characterized as developmental in nature (i.e., developmental change; Rinaldi, 2011). Drawing on the extensive identity development literature (Adams et al., 2001; Erikson, 1968; Grotevant, 1987; Hernandez, Montgomery, \& Kurtines, 2006; Kidwell, Dunham, Bacho, Pasterino, \& Portes, 1995; Marcia, 1980; Kurtines, Montgomery, Eichas, et al., 2008; Montgomery, Hernandez, \& Ferrer-Wreder, 2008; Waterman, 1999), the theoretical coders identified as theoretically meaningful a developmental progression (represented in the $\mathrm{STC}$ as $\mathrm{T} 1 \rightarrow \mathrm{T} 2 \ldots$ ) consistent with the theoretical identity literature hypothesized movement from exploration to commitment.

Because this was the first effort to empirically identify progressive structural change in both the content and structure of the subjective meaning and significance of the 
life course experiences of emerging adults, the theoretical coders drew their conceptualization on the earlier reports of Arnett's qualitative research and the emerging literature on the IDEA (Reifman, Arnett, \& Colwell, 2007). As can be seen from Figure 1, the conceptual model provided preliminary confirmatory evidence that the subjective meaning and significance of the experiences of emerging adults maps onto a developmental progression consistent with previous theoretical conceptualizations as well preliminary findings that begin to expand our empirical map of not only the structure and organization of emerging adults' sense of identity but the complex structural and organization changes involved as they undergo developmental change.

Specifically, the Level II subcategories that the theoretical analysis of the free response data yielded for the Level 1 categories of Exploring and Committed provided the first empirical evidence for the ordinary language meaning and significance of two content categories the participants used in describing their subjective life course experiences as emerging adults. For the Level 1 category of Exploring the RDA yielded two "pure" Level 2 subcategories that consisted of only content identified as focused on either issues of Independence or Self Discovery (with the Mixed subcategories for both Exploring and Committed as including responses reflecting both types of content). For example, a participant said, "Being an emerging adult to me means someone who is not yet fully an adult as far as being done with graduate school, working in the career environment you want to permanently, and being financially stable and being able to also save on the side. It also means trying to make those things happen as quickly as possible, by finishing school and being financially independent. Emerging adulthood is a very 
important stage to me because this is a period in my life where I am extremely focused on everything I'm doing in order to pursue the career and live the life I want for myself and my family in the near future."

For the Level 1 category of Committed the RDA yielded again two "pure" Level 2 subcategories that consisted of only content identified as focused on either issues of Autonomous or Self Directed (Mixed again reflecting both types of content). For example a Hispanic participant said, "Emerging adult to me means starting to take enduring decisions by yourself and not by advice of others, building your strong foundation towards the future.it is very significant because at this point in my life $\mathrm{i}$ already know what do i want out of life, what are my career goals, and expectations from a couple.”

Again drawing on the identity development literature's conceptualization concerning the basic directionality of change as well as the specific subcategories identified in our emerging adult sample, the theoretical coders identified as theoretically meaningful a developmental progression $(\mathrm{T} 1 \rightarrow \mathrm{T} 2 \ldots)$ from the Exploring subcategory of Independence to the Committed subcategory of Autonomous; from the Exploring subcategory of Self Discovery to the Committed subcategory to the Self Directed; and from the Exploring subcategory of Mixed to the Committed subcategory of Mixed.

As can also be seen from Figure 1, the conceptual model specifies developmental progression for both within and across both set of subcategories. Specifically, within the Level 1 Exploring category it specifics exploring as first the emergence of narrative expressions involving the experience of Independence followed by the emergence of 
narrative expressions involving the experience Self Discovery followed by the experience of both, i.e., having experienced of both independence and self discovery.

In a parallel but more developmentally advanced progression within the Level 1 Committed category the model specifics the emergence of a sense of Committed as first the emergence of narrative expressions involving being Autonomous followed by the emergence of Self- Directed followed by the consolidation of both, i.e. of being autonomous and self-directed.

The experiences of the emerging adults in the study thus maps onto a developmental progression consistent with previous theoretical conceptualizations as well preliminary findings that begin to expand our empirical map of not only the structure and organization of emerging adults' sense of identity but the complex structural and organization changes involved as they undergo developmental change.

Theoretical Analysis Task 2: Identifying Relations Between Categories and Identifying Structural Organizational Properties Between and Within Theoretical Categories

There are two primary aims of the second theoretical phase: 1) create a structural organization of the relations between all of the identified categories and, 2) create a structural organization of the response data within each of the identified categories (Kurtines et al., 2008). The patterns of relations between the theoretical categories (i.e., the structural organization) were examined, refined, and redefined in terms of a structural organization that was meaningful in respect to the guiding theoretical framework. Then, the theoretical coders identified the structural organization of the response data within each of the theoretical categories within each Macro Interview Response. 
For example, the structural organization of the IDEA-QE identified in the RDA was Structural Coherence (Rinaldi, 2008). Macro Interview Responsess that were characterized as cohesive and coherent were called "consolidated." Consolidation was placed in the DTC as level three. The term consolidation describes a merging of multiple elements or components into an integrated whole. Furthermore, the theoretical coders identified three subcategories of consolidation in the MIRs: unconsolidated, partially consolidated, and fully consolidated. A more comprehensive explanation of consolidation can be found in Appendix A. Theoretical Analysis Task 3: Identifying Mechanisms of Change

Because the study lacked a temporal component, the third phase of theoretical analysis was not performed.

Theoretical Analysis Task 4: Constructing a Decision Tree Chart (DTC) RDA Coding Template (RDA-CT)

The next to last step in the RDA Theoretical Analysis involves constructing an RDA-CT that is derived from the STC the results from the completion of the first two steps of the theoretical analysis. An RDA CT is constructed by first creating a DTC from the relevant RDA-STC and accompanying set of property descriptions. Such a DTC is typically created during the construction of an RDA-CT for a specific measure for a specific population, problem, etc. The purpose of an RDA-CT is to provide all of the basic information necessary to conduct an RDA Theoretical Classification Coding (TCC). Similar to the composition of any RDA-CT, components of this study's RDA-CT 
included: 1) IDEA-QE STC; 2) Theoretical Property Descriptions; 3) Theoretical Category Structural Organization; 4) RDA IDEA-QE DTC; and, 5) Coding Glossary.

The primary goal, therefore, of Theoretical Analysis Task 4 is to create the structure for the RDA Decision Tree Chart that sequentially and systematically guides the TOC and, subsequently, the TCC coder's decision making in regards to the appropriate category properties to be used for each choice in the decision making process so that each MIR is assigned to the proper category and subcategory (Kurtines et al., 2008). The Decision Tree Chart provides a tool for identifying and mapping out an effective and efficient structure for decision making. The current study modified the already existing RDA-CTs for other measures using levels as outlined by Rinaldi (2008). Level one includes the categories of Exploring and Committed, level two includes the respective subcategories of Independence, Self-Discovery, and Mixed, and level three is the consolidation (see Appendix A for the complete DTC).

A TOC was then conducted to classify the MIRs of the sample set into the corresponding categories and subcategories identified in the previous tasks of the Relational Data Analysis. The IDEA-QE-CT included levels to evaluate the inter-coder reliability at each level as well as overall category reliability. As previously discussed, RDA makes it possible to easily and readily switch between the poles of dichotomies (qualitative $\rightarrow$ quantitative, structural $\rightarrow$ causal $\rightarrow$ structural) based on the findings/results obtained in any of the phases of analysis at any level of analysis (theory and data). In this context, category levels were utilized to distinguish and further investigate the theoretical meanings of the theoretical categories identified in the TOC versus the empirical 
meanings identified in the Theoretical Open Coding. Thus, first-order level theoretical categories were identified in this study as those categories in which psychometric analysis of the RDA-CT would deem as having both theoretical meaning and empirical meaning to the current study and the RDA process as a whole and second-order level categories are those identified as having theoretical meaning to the current study but show low empirical meaning to the study through the psychometric analysis of Relational Data Analysis.

\section{Theoretical Classification Coding (TCC)}

As a final step in the RDA Theoretical Analysis Phase 4, a Theoretical Classification Coding (TCC) was conducted by a panel of theoretically neutral coders. The training of these coders was the same as the COC training, with the appropriate modifications. Copies of the same Sample Coding Deck that was used during the COC and TOC, the Coding Glossary, DCT, and the category descriptions developed in the TOC were provided. The panel then conducted the second coding procedure of the original sample set using all of the information developed during the TOC phase of RDA. Theoretical Analysis Task 5: Psychometric Analyses: Reliability and Validity Analyses of an RDA Coding Template

The last task of the RDA Theoretical Analysis is to conduct a three-step preliminary psychometric analysis (reliability and validity estimates) of the Decision Tree Chart (DTC).

Theoretical Analysis Task 5, Step 1: Estimating inter-coder reliability. The most important outcome of the conceptual and theoretical analysis phases of RDA is the 
identification of conceptual and theoretical categories; an important psychometric property of identified coding categories is the consistency with which they can be used to accurately classify participant response data into the theoretical categories (i.e., the reliability of the coding categories). Psychometric analysis of the RDA CT uses the inter-coder agreement within the TOC coders, the TCC coding, and the inter-coder agreement among the Theoretical Open Coding and the Theoretical Content Coding. This provides an independent estimate of inter-coder reliability for both the theory saturated coders and the second set of theory neutral coders that are blind to the theoretical meaning and significance of the theoretical coder's identified categories.

In this study, coder agreement was evaluated by category, subcategory, and consolidation levels identified by the TCC coders. Inter-coder agreement among the five theory-laden coders for the TCC for each of the categories was moderate to high with a range of .73 to .96 . Inter-coder percentage agreement for the TCC level one was .96, level two was .73 , and level three was .75 with a total percentage agreement across all levels of .81. Inter-coder agreement among the five theory neutral coders of the TOC for each category was moderate to high, with a range of .77 to .93 . Inter-coder percent agreement for the TOC level one was .93 , level two .77 , and level three .77 with a total percentage agreement across all levels of .82. Inter-coder agreement across the TOC and TCC was .75 with a range of .67 to .87 . Inter-coder percentage agreement for level one across the TOC and TCC was .87, level two was .67, and level three was .70.

In addition to agreement percentage, Fleiss' kappa was used to estimate the intercoder reliability of each of the levels correcting for chance. Fleiss' kappa for the TOC 
level one was estimated at .82 showing almost perfect agreement, level two was estimated at .71 showing substantial agreement, and level three was estimated at 63 showing substantial agreement. Fleiss' kappa for the TCC level one was estimated at .88 showing almost perfect agreement, level two was estimated at .64 showing substantial agreement, and level three was estimated at .60 showing moderate agreement.

Theoretical Analysis Task 5, Step 2: Estimating construct validity. As previously noted, the average inter-coder agreement across all of the categories is interpreted as providing an indirect estimate of the degree to which the conceptual properties for each of the identified categories are unique and qualitatively different from all other identified categories of the emerging grounded theory.

The overall percent agreement across all the category levels was .75 , with a range of .67 to .87 , providing evidence for a relatively high degree of construct validity for the identified categories. Because grounded theory is used in which all identified categories are not only hypothesized to be unique from each other and also represent a specific theoretically hypothesized structural organization that yields consistently higher intercoder agreement for all categories, it is interpreted as providing evidence for high reliability for each identified category as well as evidence for a high level of construct validity for all categories in the identified structural organization (Kurtines et al., 2008). In grounded theory, this includes all the other categories that make up the nomological network within which each identified category is embedded and which the classification coders (explicitly or implicitly) make use of in generating their comparative judgments with each category. In other words, the overall accuracy of the coders' classifications of 
the participant response data based on the coders' evaluation of the property of a category that is made in comparison to other category's properties provides evidence supporting the theoretically hypothesized structural organization of the categories. A high average inter-coder agreement provides evidence that each category has the theoretical meaning it is claimed to have within the context of a theoretically generated structural organization that is defined by all the other categories within which it is embedded. The psychometric properties of the $\mathrm{CT}$, therefore, provide a method for evaluating the hypothesized structural organization of the identified categories generated by the theoretical coders as well as preliminary and indirect evidence for the construct validity of the specific properties of specific categories.

\section{Theoretical Analysis Task 5, Step 3: Estimating criterion-related (concurrent)}

validity. As previously discussed, the third step of Task 5 is to use the correlation between the categories identified by theoretical coders and the category classifications generated by a second set of theory neutral conceptual coders to estimate the concurrent (external) validity of the coded categories. In this step, the resulting correlation coefficient is interpreted as a coefficient of concurrent validity (a type of criterion-related validity) (Kurtines et al., 2008). The focus of the analysis is on the concurrent validation of multi-manifestations of the same theoretical construct generated by multiple methods (open coding by theory-laden coders versus the classification coding by an independent sample of theory neutral coders) as opposed to predictive validity (Kurtines et al., 2008). The correlation between the modal Coding Category, by level, that the theoretical coders (TOC) assigned to each participant's MIR and the modal Coding Category, by level, that 
the theory neutral coders (TCC) assigned to each participant's MIR was, $r(31)=.65$, $\mathrm{p}<$ .001 , for level one, $r(31)=.70, \mathrm{p}<.001$ for level two, and $r(31)=.74, \mathrm{p}<.001$ for level three, providing evidence for medium to high concurrent (external) validity for the identified theoretical categories. The theoretical categories that were consensually identified in the theoretical analysis, as previously discussed, are theoretically meaningful and also are rooted in the content properties that exist in the raw data (i.e., they have conceptual meaning independent of their theoretical meaning). Therefore, the concurrent validation, in contrast to conceptual and theoretical analysis, does not use open coding to identify concepts (categories); rather, the TCC coding is used to classify the data into categories that were identified during the theoretical analysis (Kurtines et al., 2008). The concurrent (external) validity of the categories is estimated by the correlation between the theoretical categories generated by the theoretical coders' open coding of the raw data responses and the classification of the same original raw data responses into the same theoretical categories by a second set of theory neutral coders. 


\section{DISCUSSION}

As a new area of research since its inception in 2000, emerging adulthood research has grown substantially. Key features have been attributed to this time of life and measures have been created to study them, i.e., the Identity Dimensions of Emerging Adulthood (IDEA) instrument. However, there is still a great deal to understand about EA. For instance, there is little research on the specific trajectories and experiences of this time of life for different populations (i.e., college versus non-college populations, minority versus majority populations, male versus female populations) as well as a lack of research on the meaning and significance of EA for individuals. Arnett (2006) argued that qualitative research is the most appropriate methodology to begin to addresses these gaps in research.

This study supplements current EA research in multiple ways. First, FIU's location in South Florida has implications for the demographic makeup of the study and FIU is compromised primarily of Hispanics (60\%; FIU, 2010). This study's population sample expanded on emerging adult research. The Hispanic population is often understudied and there is limited research on the Hispanic emerging adults as the majority of research on emerging adulthood uses White Non-Hispanic participants.

In addition, it answers the call for qualitative research. Arnett (2006) urged more qualitative research in the emerging adult field. Because of the unique nature and characteristics of emerging adulthood, Arnett (2006) argues that such research is not only important but also imperative. Specifically, emerging adults' self-focus makes them highly capable of self-cognition which can most comprehensively be captured with free- 
response research (Arnett, 2006). The heterogeneity and variability of experiences of emerging adulthood also can best be captured with free-response data and, more specifically, the relational approach of Relational Data Analysis.

First, FIU's location in South Florida has implications for the demographic makeup of the study and FIU is compromised primarily of Hispanics (60\%; FIU, 2010). This study's population sample expanded on emerging adult research. The Hispanic population is often understudied and there is limited research on the Hispanic emerging adults as the majority of research on emerging adulthood uses a White Non-Hispanic participants.

Qualitative research, however, is often problematic as it is complex and timeconsuming. By using the Qualitative Extension (QE) methodology, this study effectively and easily developed a qualitative extension to a quantitative measure that examines the characteristics of emerging adulthood. The Identity Dimensions of Emerging AdulthoodQualitative Extension (IDEA-QE) measure that was used in this study furthered this inquiry to include the meaning and significance of the characteristics, broadening the scope of research using a qualitative methodology.

Second, it extends the use of Relational Data Analysis (RDA). Previous research on RDA utilized the framework for use with at-risk adolescents as a part of the Changing Lives Program (CLP). This study was undertaken as part of the pilot research of the Adult Development Project, which broadens the CLP for use with emerging adults. This extension is important, as RDA research analyses test and evaluate evolving theoretical perspectives against the evolving developmental and socio-cultural historical reality that 
is evident in the changing content and structural organizational properties in the participant's free response data as captured and rendered explicit and intelligible by the COC and TOC coding processes of Relational Data Analysis (Kurtines et al., 2008). Importantly, with regards to knowledge development when used within repeated measures designs to analyze unstructured free response data, RDA helps to ensure that in such research designs the $\mathrm{COC}$ and TOC phases of the RDA analysis will uncover new categories of life course experience as they emerge at the leading edge of developmental and historical change (Kurtines et al., 2008). Thus, RDA maximizes the likelihood that new content categories identified during conceptual analysis will not be obscured or overlooked. The researcher and theoretical research team is challenged to then transform these conceptual categories into theoretically meaningful constructs and concepts and, ultimately, into data driven theoretical hypotheses to be evaluated by both quantitative and qualitative data analytic strategies. This study's utilization of RDA, therefore, expands the scope of previous, primarily quantitative research on emerging adulthood.

Developmental intervention scientists have become increasing more interested in contributing to in the analysis and interpretation of intervention, developmental, and historical change (Kurtines et al., 2008). Regarding change at the intervention and developmental level, RDA as a data analytic strategy and the work on development of qualitative measures and methods capable of capturing and analyzing qualitative intervention and developmental change intersect with the broader interest of historical change as reflected in changes in the subjective meaning and significance of life course experiences, as these are interpreted by the researcher and as interpreted by participants 
themselves.

Additionally, RDA extends the standard system theory hierarchical structural organization model to include a fourth, non-hierarchical, non-structural, nonorganizational component: a temporal component, which depicts change over time (represented by $\mathrm{T} 1 \rightarrow \mathrm{T} 2 \ldots$ ), focusing on a specific pattern of change and successive change over time that can be characterized as developmental in nature (i.e., developmental change; Rinaldi, 2011). Consistent with this theory, theoretical coders in this study found such a developmental progression of the Exploring to Committed categories and their subcategories. With regards to developmental progression, theoretical coders identified Exploring-Independence $\mathrm{T} 1 \rightarrow \mathrm{T} 2 \ldots$ Committed-Autonomy, Exploring-Self-Discovery T1 $\rightarrow$ T2 ...Committed-Self-Directed, and Exploring-Mixed $\mathrm{T} 1 \rightarrow \mathrm{T} 2$...Committed-Mixed. Emerging adulthood theory (i.e., Arnett, 2004; 2006) argues that exploring one's identity and adult roles is fundamental to their period of life, with commitment to them marking the end of this phase of life. The use of RDA and these findings enhance emerging adult theory and previous research by theoretically meaningful and qualitatively rich descriptions of the meaning and significance of possible transformations from identity exploration of adult roles to committing to them looks life in the real world with this cross-sectional data. Because the raw data was the subjective narrative experiences of emerging adulthood described by the participants themselves without restrictions, this study was provided a picture of what emerging adulthood is and what progression through it might look like. 
Relational Data Analysis also provides a framework for analyzing the psychometric properties of qualitative data. Previous qualitative research on emerging adulthood, including the interview-based qualitative research used by Arnett to characterize and define emerging adulthood did not include comprehensive, replicable psychometric analyses. The use of RDA serves to facilitate the evaluation of the psychometric properties the theoretically meaningful categories identified by the analyses. Moreover, a literature has begun to emerge on the acceptability of RDA's psychometric properties of RDA templates. Psychometric analyses indicated acceptable reliability and validity for multiple measures using an at-risk adolescent population (Lewis Arango et al.,2008; Kortsch et al., 2008; Ritchie, 2007; Rinaldi, 2008). Prior to this study, however, research using the RDA framework was limited to an at-risk adolescent population. This study expands the use of RDA for use with an emerging adult population and showed similar acceptable psychometric properties as previous RDA research indicated.

\section{Limitations}

Though this study enhances emerging adult research and expands research using RDA, there are some limitations. A limitation of this study is its sampling. The participants voluntarily enrolled in an elective psychology course. Most participants, therefore, are psychology majors though there are some majors from related fields (i.e., social work, criminal justice). As college students enrolled in a four-year university, the findings' generalizability is limited. In addition, the large percentage of Hispanics in this study makes the generalizability limited to the focal group. 
A related limitation is sample size. This study's sample was 70 participants, with a subsample of 31 participant's responses being used in the codings. Though this is a relatively small number, the RDA framework used in this study was able to capture change and create categories and their structural organization with acceptable psychometric properties. Future research should include a larger sample to capture more change and possibly new, unique categories.

Additionally, participants may not be forthcoming on some of the more sensitive questions asked on the measures. This study attempted to minimize this risk by having the study be web-based where the participants can take the measures privately at their convenience.

\section{Conclusion}

The study reported in this paper, undertaken as the first stage psychometric evaluation of measures, provides evidence that the measure under development (the IDEA-QE) has acceptably high psychometric properties (i.e., reliability and validity) across the categories, most notably at the first order level of the theoretical categories. These findings support the undertaking a full-scale short-term controlled outcome trial and evidence for a framework in which to utilize the IDEA-QE in evaluation of the Changing Lives Program positive development program for use with emerging adults. 


\section{REFERENCES}

Adams, G.R., Munro, B., Doherty-Poirer, B., Munro, G., Petersen, A.R., \& Edwards, J. (2001). Diffuse-avoidance, normative, and informational identity styles: Using identity theory to predict maladjustment. Identity, 1(4), 307-320.

Anastasi, A., \& Urbina, S. (1997). Psychological testing (7th ed.). Upper Saddle River, NJ: Prentice-Hall.

Archer, S.L. (Ed). (1994). Interventions for adolescent identity development. Thousand Oaks, CA: Sage.

Arnett, J.J. (1994). Are college students adults? Their conceptions of the transition to adulthood. Journal of Adult Development, 1, 154-158.

Arnett, J.J. (1995). Broad and narrow socialization: The family in context of cultural theory. Journal of Marriage and the Family 57, 617-628.

Arnett, J.J. (1997). Young people's conceptions of the transition to adulthood. Youth \&Society, 29, 1-23.

Arnett, J.J. (1998). Learning to stand alone: The contemporary American transition to Adulthood in cultural and historical context. Human Development,. 41(5-6), 295480 .

Arnett, J.J. (2000). Emerging adulthood: A theory of development from the late teens Through the twenties. American Psychologist, 55(5): 469-480.

Arnett, J.J. (2001). Conceptions of the transition to adulthood: Perspectives from adolescence to midlife. Journal of Adult Development, 8, 133-143.

Arnett, J.J. (2003). Conceptions of the transitions to adulthood among emerging adults in American ethnic groups. New Directions in Child and Adolescent Development, 100, 63-75.

Arnett, J.J. (2004). Emerging adulthood: The winding road from the late teens through the twenties. New York: Oxford University Press.

Arnett, J.J. (2006). The psychology of emerging adulthood: What is known, and what remains to be known?. In J.J. Arnett \& J.L. Tanner (Eds.), Emerging adulthood: Coming to age in the twenty first century (pp. 303-330). Washington, D.C.: American Psychological Association 
Arnett, J.J. (2007). Suffering, selfish, slackers? Myths and reality about emerging adults. Journal of Youth and Adolescence, 36, 23-29.

Arnett, J.J., \& Taber, S. (1994). Adolescence terminable and interminable: When does adolescence end? Journal of Youth and Adolescence, 23, 517-537.

Berman, S.L., Kennerly, R.J., \& Kennerly, M.A. (2008). Promoting adult identity development: A feasibility study of a university-based identity intervention program. Identity, 8(20), 139-150.

Berman, A.M., Schwartz, S.J., Kurtines, W.M., \& Berman, S.L. (2001). The process of exploration in identity formation: The role of style and competence. Journal of Adolescence, 24, 513-528.

Blos, P. (1962). On adolescence: A psychoanalytic interpretation. New York: Free Press.

Briggs, C.L. (1989). Learning how to ask: A sociolinguistic appraisal of the role of the interview in social science research. New York: Cambridge University Press.

Campbell, D.T. \& Fiske, D.W. (1959). Convergent and discriminant validation by the multitrait-multimethod matrix. Psychological Bulletin, 56, 81-105.

Cote, J.E. (2000). Arrested adulthood: The changing nature of maturity and identity in the late modern world. New York: University Press.

Cote, J.E., \& Allahar, A.L. (1994). Generations on hold: Coming of age in the late twentieth century. Toronto, Canada: Stoddart.

Cote, J.E., \& Levine, C. (1997). Student motivations, learning environments, and human capital acquisition: Toward an integrated paradigm of student development. Journal of College Student Development, 38(3), 229-243.

Cote, J.E., \& Levine, C. (2000). Attitude versus aptitude: Is intelligence or motivation more important for positive higher-education outcomes? Journal of Adolescent Research, 15, 58-80.

Cote, J.E., \& Roberts, S. (2003, May). Monitoring the transition to adulthood: The Identity Stage Resolution Index. Paper presented at the annual meeting of the Society for Research on Identity Formation, Vancouver, B.C., Canada.

Dwyer, P., \& Wyn, J. (2001). Youth, education, and risk: Facing the future. London: Routledge/Falmer. 
Eichas, K., Albrecht, R.E., Garcia, A.J., Ritchie, R.A., Varela, A., Garcia, A., Rinaldi, R., Montgomery, M.J., Silverman, W.K., Jaccard, J., \& Kurtines, W.M. (2010). Mediators of positive youth development intervention change: Promoting change in positive and problem outcomes? Child and Youth Care Forum.

Elder, G. (1998). The life course and human development. In R. M. Lerner (Ed.), Handbook of child psychology, Vol. 1: Theoretical models of human development. New York, NY: Wiley.

Enright, R.D., Ganiere, D.M., Buss, R.R., Lapsley, D.K., \& Olson, L.M. (1983). Promoting identity development in adolescents. Journal of Early Adolescence, 3, 247-255.

Erikson, E.H. (1968). Identity: Youth and crisis. New York: Norton.

Ferrer-Wreder, L.A., Montgomery, M.J., \& Lorente, C.C. (2003). Identity promotion in adolescence. In T. Gullotta, J. Bloom, \& G. Adams (Eds.), Encyclopedia of primary prevention and health promotion (pp. 600-607). Highman, MA: Kluwer Academic/Plenum.

Fleiss, J.L. (1973). Statistical Methods for Rates and Proportions. John Wiley and Sons, New York .

Friere, P. (1983). Pedagogy of the oppressed. New York: Herder \& Herder.

Furlong, A., \& Cartamel, F. (1997). Young people and social change: Individualization and risk in late modernity. Buckingham: Open University Press.

Grob, A., Krings, F., \& Bangerter, A. (2001). Life markers in biographical narratives of people from three cohorts: A life span perspective in its historical context. Human Development, 44, 171-190.

Grotevant, H.D. (1987). Toward a process model of identity formation. Journal of Adolescent Research, 2(3), 203-222.

Helson, R., \& Roberts, B.W. (1994). Ego development and personality change in adulthood. Journal of Personality and Social Psychology, 66, 911-920.

Henninghausen, K.H., Hauser, S.T., Billings, R.L., Schultz, L.H., \& Allen, J.P. (2004). Adolescent ego-development trajectories and young adult relationship outcomes. Journal of Early Adolescence, 24, 29-44.

Hernandez, L., Montgomery, M., \& Kurtines, W.M. (2006). Identity distress and adjustment problems in at-risk adolescents. Identity, 6(1), 27-33. 
Karlin, J. \& Borofsky, A. (Eds.) (2003). ReGeneration: Telling stories from our twenties. New York: Tarcher/Putnam.

Kidwell, J.S., Dunham, R.M., Bacho, R.A., Pastorino, E., \& Portes, P.R. (1995). Adolescent identity exploration: A test of Erikson's theory of transitional crisis. Adolescence, 30(120), 785-793.

Kortsch, G., Kurtines, W. M., \& Montgomery, M. J. (2008). Promoting Positive Youth Development: The Reliability, Validity, and Utility of the Possible Selves Questionnaire (PSQ) in the Evaluation of the Changing Lives Program (CLP). Journal of Adolescent Research.

Kurtines, W. M., Montgomery, M. J., Arango, L. L., Kortsch, G., Albrecht, R., Garcia, A., Ritchie, R., \& Eichas, K. (2008). Promoting positive youth development: Relational data analysis (RDA). Journal of Adolescent Research, 23(3), 291-309.

Lasser, V., \& Snarey, J. (1989). Ego development and perceptions of parent behavior in adolescent girls: A qualitative study of the transition from high school to college. Journal of Adolescent Research, 4, 319-355.

Lerner, R. M. (2002). Concepts and theories of human development $\left(3^{\text {rd }} \mathrm{ed}.\right)$. Mahwah,NJ: Lawrence Erlbaum.

Lerner, R.M., Almerigi, J.B., Theokas, C. (2005). Positive youth development: A view of the issues. Journal of Early Adolescence, 25, 10-16.

Lewis-Arango, L. L., Kurtines, W. M., Montgomery, M. J., \& Ritchie, R. (2008). A multi-stage longitudinal comparative design stage II evaluation of the Changing Lives Program: The Life Course Interview (RDA-LCI). Journal of Adolescent Research, 23(3), 310-341.

Marantz Hegin, R. (2010, August 18). What is it about 20 somethings?. New York Times, p. MM28.

Marcia, J.E. (1980). Identity in adolescence. In J. Adelson (Ed.), Handbook of adolescent psychology (pp. 103-137). New York: Wiley \& Sons.

Markstrom-Adams, C., Ascione, F.R., Braegger, D., \& Adams, G.R. (1993). The effects of two forms of perspective taking on ego identity formation in late adolescence. Journal of Adolescence, 16, 217-224.

Meilman, P.W. (1979). Cross-sectional age changes in ego identity status during adolescence. Developmental Psychology, 15, 230-231. 
Montgomery, M. J., Kurtines, W. M., Ferrer-Wreder, L., Berman, S. L., Lorente, C. C., Briones, E., Silverman, W., Ritchie, R., \& Eichas, K. (2008). A Developmental Intervention Science (DIS) outreach research approach to promoting youth development: Theoretical, methodological, and meta-theoretical challenges. Journal of Adolescent Research, 23(3), 268-290.

Nelson, L.J. (2003). Rites of passage in emerging adulthood: Perspectives of young Mormons. New Directions in Child and Adolescent Development, 100, 33-49.

Nunnally, J. C. (1978). Psychometric theory (2nd ed.). New York: McGraw-Hill.

Overton, W. F. (2006). Developmental psychology: Philosophy, concepts, methodology. In R.M. Lerner (Ed.) Theoretical models of human development (pp. 18-88). (6th ed.), New York: Wiley.

Pumain, D. (2006). Hierarchy in Natural and Social Sciences. New York, NY: SpringerVerlag.

Reifman, A., Arnett, J.J., \& Colwell, M.J. (2007, Summer). Emerging adulthood: Theory, assessment, and application. Journal of Youth Development, 2(1). Retrieved from http://www.nae4ha.org/directory/jyd/index.html.

Rinaldi, R.L., Meca, A., Eichas, K., Kurtines, W.M., Ritchie, R., Albrecht, R., \& Goodletty, S. (under review). Deciding between fixed or free response data... why not both?: A relational data analysis approach.

Rinaldi, R. (2011). A Developmental Intervention Science Outreach Research Approach to Promoting Positive Youth Development. Unpublished Dissertation. Florida International University, Miami.

Ritchie, R. (2007). The Development and Refinement of a Generic Coding Template for Enhancing the Utility, Reliability and Validity of Relational Data Analysis Theoretical Classification Coding (RDA-TCC). Unpublished Thesis. Florida International University, Miami.

Robbins, A. \&Wilner, A. (2001). Quarterlife crisis: The unique challenges of life in your twenties. New York: Tarcher/Putnam.

Schultz, L.H., \& Selman, R.L. (1998). Ego development and the interpersonal development in young adulthood: A between-model comparison. In P.M. Westenberg, A. Blasi, L.D. Cohen (Eds.), Personality development: Theoretical, empirical, and clinical investigations of Loevinger's conception of ego development (pp. 181-202). Mahwah, NJ: Erlbaum. 
Schwartz, S.J., Cote, J.E., \& Arnett, J.J. (2005). Identity and agency in emerging adulthood: Two developmental routes in the individuation process. Youth and Society, 37(2), 201-229.

Schwartz, S.J., Kurtines, W.M., \& Montgomery, M.J. (2005). A comparison of two approaches for facilitating identity exploration in emerging adults: An exploratory study. Journal of Adolescent Research, 20(3), 309-345.

Strauss, A., \& Corbin, J. (1998). Basics of qualitative research: Techniques and Procedures for Developing Grounded Theory. Thousand Oaks, CA: Sage.

Tanner, J.L. (2006). Recentering during emerging adulthood: A critical turning point in life span human development. In J.J. Arnett \& J.L. Tanner (Eds.), Emerging adulthood: Coming to age in the twenty first century (pp. 21-56). Washington, D.C.: American Psychological Association

Waterman, A.S. (1999). Identity, the identity statuses, and identity status development: a contemporary statement. Developmental Review, 19(4), 591-621.

Wittgenstein, L. 1953. Philosophical investigations. (Anscombe, G.E.M., trans.). Oxford: Basil Blackwell.

Zimmerman, M.A. (1995). Psychological empowerment: Issues and illustrations. American Journal of Community Psychology, 23(5), 581-599. 


\section{APPENDIX}

Appendix A: IDEA-QE RDA-CT

1. The IDEA-QE STC

2. Theoretical Category Property Descriptions

3. Theoretical Category Structural Organization

4. RDA IDEA-QE DTC

5. Coding Glossary 


\section{Appendix A:}

\section{IDEA-QE RDA-CT}

The Identity Dimensions of Emerging Adulthood-Qualitative Extension (IDEAQE) builds on the pioneering worth of Reifman, Arnett, and Colwell (2007) in the development of the Identity Dimensions of Emerging Adulthood (IDEA) and the literature on emerging adulthood (e.g., Arnett's theory of emerging adulthood). The IDEA measures identification with emerging adulthood themes described by Arnett (2004; 2006), including identity exploration, experimentation, negativity, other-focused, self-focused, and in-between using a Likert-like scale format. As part of the Adult Development Project (ADP), the IDEA is administered and scored as originally developed by Reifman, Arnett, and Colwell (2007).

After participants have completed the standard IDEA ratings, the standard Qualitative Extension (QE) module for eliciting free response narrative data is completed. Thus, the Identity Dimensions of Emerging Adulthood-Qualitative Extension (IDEA-QE) extends the standard IDEA instrument by providing a method for eliciting participant's open-ended narrative descriptions of the subjective meaning and significance of the experiences of emerging adulthood, which are analyzed within the Relational Data Analytic framework.

Specifically, in the IDEA-QE measure, participants choose the most important two of these five characteristics for themselves. Specifically, they are asked "Of the five features described above [Arnett's five features of EA are described], which two do you believe come closest to your experience of emerging adulthood?" Then, participants are 
asked about which is the most indicative for themselves. The question is "Of these two, which do you believe has been your most characteristic or important experience?" The measure also asks about the meaning and significance of emerging adulthood for the participant ("What does being an emerging adult mean to you?" and "How is it significant or important to you?"). For this study, only the meaning and significance questions were examined using Relational Data Analysis (RDA). 
Figure 1. RDA IDEA-QE Structural Tree Chart

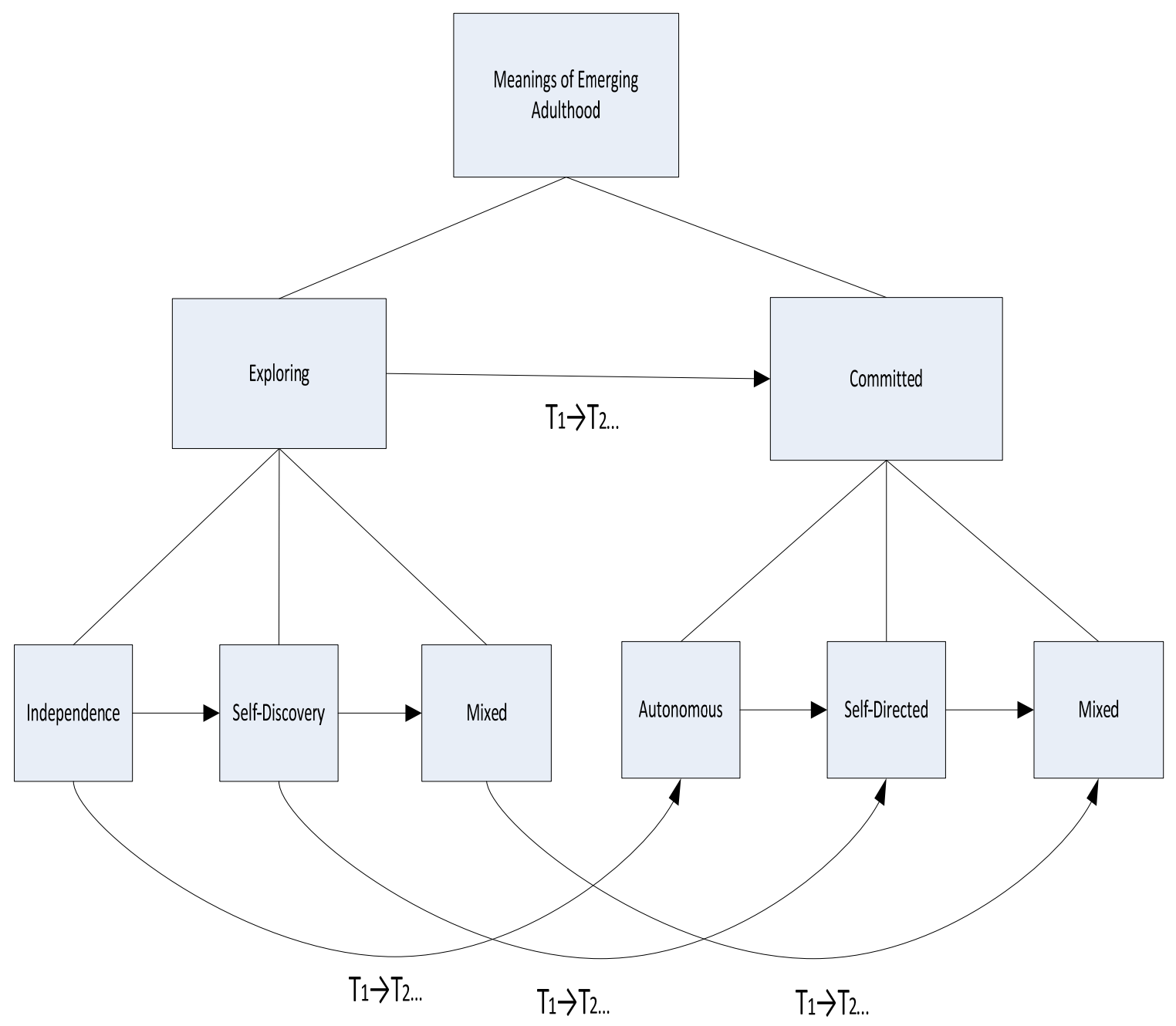




\section{Theoretical Category Property Descriptions}

The IDEA-QE STC Property Descriptions for the identified theoretical categories were reported as follows.

\begin{tabular}{|c|c|}
\hline Property Description & Sample Responses \\
\hline \multicolumn{2}{|c|}{$\begin{array}{l}\text { I. Exploring } \\
\text { The unique property of the Exploring Level } 1 \text { subcategory was that the description of the } \\
\text { meaning and significance of Emerging Adulthood (EA) included reference to exploration of self } \\
\text { or of adult roles. According to Arnett (2004) and Tanner (2006), explorations of the self and adult } \\
\text { roles are a key feature of EA. Adult roles include gaining financial independence (paying one's } \\
\text { own bills, etc.), maintaining a job and/or beginning to make career choices, adult relationships, } \\
\text { and taking on adult responsibilities. Exploring the self includes figuring out who you are and } \\
\text { what you want out of life (Arnett, 2004). This exploration of the self and roles are a characteristic } \\
\text { of being an emerging adult. The coders agreed that the properties of this category that make it } \\
\text { different from the Commitment level } 1 \text { subcategory, was that commitment to adult roles and self } \\
\text { are indications of completion of this time of life (i.e., EA). These responses, therefore, made no } \\
\text { reference to committing to adult roles or definition of self/identity. }\end{array}$} \\
\hline $\begin{array}{l}\text { 1) Independence. The unique property of the } \\
\text { Independence Level } 2 \text { subcategory was that the } \\
\text { description of the meaning and significance of EA } \\
\text { included reference to adult roles and responsibilities. } \\
\text { Arnett (2004) and Tanner (2006) argue that EA is a part } \\
\text { of the lifespan where individuals focus on becoming } \\
\text { (i.e., Exploring) self-sufficient and take on more and } \\
\text { more adult responsibilities and roles. The individual is } \\
\text { moving from being a dependent adolescent to an } \\
\text { independent adult. The responses assigned to this } \\
\text { subcategory discuss becoming self-sufficient and } \\
\text { gaining adult sufficiency and strictly only mention the } \\
\text { exploration of adult roles and no mention of exploring } \\
\text { the self. Tasks such as gaining financial independence } \\
\text { (paying one's own bills, etc.), maintaining a job and } \\
\text { beginning to make career choices, adult relationships, } \\
\text { participation in higher education, and taking on adult } \\
\text { responsibilities are discussed in the responses. There was } \\
\text { no mention of the exploration of the self or identity, } \\
\text { which the coders agreed was the property that makes } \\
\text { these responses different from the Self-Discovery } \\
\text { subcategory, and commitments to the roles and } \\
\text { responsibilities have not been made. In addition, no } \\
\text { commitments to adult roles/responsibilities are } \\
\text { discussed, making this subcategory distinct from the } \\
\text { Committed-Autonomy category. }\end{array}$ & $\begin{array}{l}\text { In response to the questions of what } \\
\text { emerging adulthood means and how } \\
\text { significant or important is it to you, } \\
\text { one participant responded, "Being an } \\
\text { emerging adult to me means someone } \\
\text { who is not yet fully an adult as far as } \\
\text { being done with graduate school, } \\
\text { working in the career environment } \\
\text { you want to permanently, and being } \\
\text { financially stable and being able to } \\
\text { also save on the side. It also means } \\
\text { trying to make those things happen as } \\
\text { quickly as possible, by finishing } \\
\text { school and being financially } \\
\text { independent. Emerging adulthood is a } \\
\text { very important stage to me because } \\
\text { this is a period in my life where I am } \\
\text { extremely focused on everything I'm } \\
\text { doing in order to pursue the career } \\
\text { and live the life I want for myself and } \\
\text { my family in the near future." }\end{array}$ \\
\hline
\end{tabular}




\begin{tabular}{|c|c|}
\hline Property Description & Sample Responses \\
\hline $\begin{array}{l}\text { 2) Self-Discovery. The unique property of the Self- } \\
\text { Discovery Level } 2 \text { subcategory was that the description } \\
\text { of the meaning and significance of EA included } \\
\text { reference to the self and transitioning from adolescence } \\
\text { to adulthood. According to Arnett (2004) and Tanner } \\
\text { (2006), EA is a time of self-discovery (figuring out who } \\
\text { you are) as you make the transition to adulthood. } \\
\text { Identity exploration is key during this time of life. } \\
\text { These responses reference the self and make no } \\
\text { reference to adult roles or responsibilities and only } \\
\text { mention the goal of moving towards adulthood. } \\
\text { References to figuring out who you are and answering } \\
\text { the question "Who am I?" are evident in these } \\
\text { responses. There is a general discussion of the self and } \\
\text { talk about choices broadly without committing to them. } \\
\text { This subcategory is different from the Independence } \\
\text { subcategory because there is no reference to adult roles } \\
\text { or responsibilities in the responses. In addition, no } \\
\text { commitments to self/identity are discussed, making this } \\
\text { subcategory distinct from the Committed-Self-Directed } \\
\text { category. }\end{array}$ & $\begin{array}{l}\text { In response to the questions of what } \\
\text { emerging adulthood means and how } \\
\text { significant or important is it to you, } \\
\text { one participant responded, "it means } \\
\text { all the steps you have to take to } \\
\text { become an adult... the time to mature } \\
\text { and learn more about who you really } \\
\text { are... super important. since my teen } \\
\text { years i have felt like i dont know who } \\
\text { i really am, so this period of time is } \\
\text { when i hope i can find my self." }\end{array}$ \\
\hline $\begin{array}{l}\text { 3) Mixed. The unique property of the Mixed Level } 2 \\
\text { subcategory was that the description of the meaning and } \\
\text { significance of EA included references to both adult } \\
\text { roles and responsibilities as well as references to the self } \\
\text { and identity exploration. Adult roles and responsibilities } \\
\text { are referenced without any commitments to them. In } \\
\text { addition, the self and identity are referenced but no } \\
\text { distinct commitments to them are discussed, unlike the } \\
\text { responses in the Committed-Mixed category. }\end{array}$ & $\begin{array}{l}\text { In response to the questions of what } \\
\text { emerging adulthood means and how } \\
\text { significant or important is it to you, } \\
\text { one participant responded, "It means } \\
\text { one's actually growing up. One is } \\
\text { becoming independent. It is a stage of } \\
\text { transitions and growth. Growth of the } \\
\text { senses and emotions. It's is extremely } \\
\text { important to me. It's a time where I } \\
\text { am establishing my true identity and } \\
\text { career and future goals. Reality is } \\
\text { hitting." }\end{array}$ \\
\hline
\end{tabular}




\section{Committed.}

The unique property of the Committed Level 1 subcategory was that the meaning and significance of EA referenced commitments to adult roles and self/identity. The subjective narrative description referenced already being committed to adult roles and self discovery. According to Arnett (2004) and Tanner (2006), individuals who have made adult role commitments and established an identity have moved towards adult sufficiency and out of emerging adulthood. Adult role commitments and responsibilities, such as gaining financial independence (paying one's own bills, etc.), maintaining a job and beginning to make career choices, adult relationships, and taking on adult responsibilities, have been made. The process of self-discovery and figuring out who you are has been completed. These responses include reference to knowing who they are and what they want to do, be, etc.

1) Autonomous. The unique property of the Autonomous Level 2 subcategory was that the description of the meaning and significance of EA included reference to adult roles and responsibilities. Arnett (2004) and Tanner (2006) argue that EA is a part of the lifespan where individuals focus on becoming self-sufficient and take on more and more adult responsibilities and roles. The individual has moved from being a dependent adolescent to an independent adult. The responses discuss being self-sufficient and gaining adult sufficiency. Tasks such as gaining financial independence (paying one's own bills, etc.), maintaining a job and beginning to make career choices, adult relationships, participation in higher education, and taking on adult responsibilities and their commitments to them are discussed in the responses. There is no discussion of the self or identity, which the coders agreed was the property that makes these responses different from the Self-Directed subcategory.
In response to the questions of what emerging adulthood means and how significant or important is it to you, one participant responded, "emerging adult to me means starting to take enduring decisions by yourself and not by advice of others, building your strong foundation towards the future.it is very significant because at this point in my life $i$ already know what do i want out of life, what are my career goals, and expectations from a couple" 


\begin{tabular}{|c|c|}
\hline Property Description & Sample Responses \\
\hline $\begin{array}{l}\text { 2) Self-Directed. The unique property of the Self- } \\
\text { Directed Level } 2 \text { subcategory was that the description of } \\
\text { the meaning and significance of EA included reference } \\
\text { to the self and transitioning from adolescence to } \\
\text { adulthood. According to Arnett (2004) and Tanner } \\
\text { (2006), EA is a time of self-discovery (figuring out who } \\
\text { you are) as you make the transition to adulthood. } \\
\text { Identity exploration is key during this time of life. } \\
\text { These responses reference the self and make no } \\
\text { reference to adult roles or responsibilities and talk about } \\
\text { the abstract goal of moving towards adulthood. The } \\
\text { responses reference knowing the answer to the question } \\
\text { "who am I?". There is a general discussion of the self } \\
\text { and talk about their commitment to choices. This } \\
\text { subcategory is different from the Independence } \\
\text { subcategory because there is no reference to adult roles } \\
\text { or responsibilities in the responses. }\end{array}$ & $\begin{array}{l}\text { In response to the questions of what } \\
\text { emerging adulthood means and how } \\
\text { significant or important is it to you, } \\
\text { one participant responded, "The } \\
\text { freedom to discover who you are and } \\
\text { to find out what are the things you } \\
\text { like or dislike in life. I am } 34 \text { years } \\
\text { old. Not important." }\end{array}$ \\
\hline $\begin{array}{l}\text { 3) Mixed. The unique property of the Mixed Level } 2 \\
\text { subcategory was that the description of the meaning and } \\
\text { significance of EA included references to both adult } \\
\text { roles and responsibilities as well as references to the self } \\
\text { and identity exploration. Adult roles and responsibilities } \\
\text { are referenced in regards to the commitments to them. } \\
\text { These responses reference personal identity and adult } \\
\text { role commitments. In addition, the self and identity are } \\
\text { referenced without any commitments either. }\end{array}$ & $\begin{array}{l}\text { In response to the questions of what } \\
\text { emerging adulthood means and how } \\
\text { significant or important is it to you, } \\
\text { one participant responded, "to me it } \\
\text { means accepting new challenges and } \\
\text { good events as they come and } \\
\text { learning to cope and work on them in } \\
\text { a rational mature manner and } \\
\text { realizing it is time to grow up. i grew } \\
\text { up very quickly in my family so it is } \\
\text { important to me to surround myself } \\
\text { with responsible mature people." }\end{array}$ \\
\hline
\end{tabular}


3. Identity Dimensions of Emerging Adulthood-Qualitative Extension (IDEA-QE)

Theoretical Category Structural Organizational Property Description Structural Organizational Property Description Overview

Structural organizational Properties are coded at the level of the Macro Interview Response (MIR)

- Macro Interview Response (MIR) -- a narrative transcription that includes all the words, phrases, and sentences the participant used in describing the meaning and significance of the experience (topic, issue, question, etc.) under investigation.

\section{Structural Coherence}

The primary structural organizational property we have identified for the LCI is Structural Coherence - the degree to which the overall structure and organization of an MIR may be considered a cohesive and coherent expression of a sense of "Who you are." - One's sense of identity

We characterize a cohesive and coherent expression of a sense of identity as "consolidated."

Consolidation -- a merging of the multiple elements or components of the self into of an integrated whole

We have identified three sub-categories of Consolidation: Unconsolidated, Partially Consolidated, and Fully Consolidated. Each sub-category is defined by variation along the following structural organizational properties: Diversity/Variety, Elaboration/Articulation, and Differentiation/Integration 
Diversity/Variety (MIRs are classified according to the number or frequency of distinct and different RCUs an MIR contains and the degree of variability within each different type of RCU)

- Diversity - refers to the number or frequency of distinct and different RCUs. That is, number of explicit references to distinct or different personality variables, affective variables, cognitive variables, etc. that the MIR contains.

- Variety - refers to the degree of variability within each different type of RCU an MIR contains. For instance, variability in different types of personality variables (e.g., traits, goals, accomplishments, etc.), types of affective variables (e.g., feelings or mood states such as anger, confusion, helplessness, etc.), types of cognitive variables (e.g., thoughts, ideas, attitudes, belief, etc). An MIR may contain a single RCU describing only one personality variable, but with extensive primary and secondary elaboration; two, three, or more different types of personality variables with primary and secondary elaboration and no affective or cognitive variables; or two, three, or more different types of personality variables and two, three, or more different types of affective variables with primary and secondary elaboration; etc.

Elaboration/Articulation (MIRs are classified according to the number or frequency of elaboration (primary and secondary) and the degree to which the elaborations are articulated) 
- Primary Elaboration (PE) - refers to an initial reason, justification, rationale for a particular narrative response.

- Secondary Elaboration (SE) -- refers to additional reasons, justifications rationales given to provide more thoughtful attention to parts or details of reason already given.

- Articulation - refers to the degree to which the joining or bringing together words and utterances in elaborations (primary or secondary) is expressed in a creative or refined way and/or is intricate and rich in detail and/or with a great deal of thoughtful specificity and explicitness.

\section{Differentiation/Integration}

- Differentiation (DIF) - refers to the degree to which an MIR contains primary or secondary elaboration making distinctions and/or discriminating among RCUs along either a horizontal or vertical temporal dimension. A horizontal temporal dimension refers to making distinctions among two or more RCUs (e.g., personality variables) at the same point in time (either past, present, or future). For instance, "My [current] goals in life are to accomplish A and B, and B is more [or less] important [significant, meaningful, etc.] to me.” A vertical temporal dimension refers to making distinctions among two or more RCUs (e.g., personality variables) across (over) time (e.g., from the past to the present or the future). For instance, "When I was younger my goals in life were to accomplish A and B; however, B is no longer [or less] important [significant, meaningful, etc.] to me now than A." Primary or secondary elaboration making distinctions and/or 
discriminations involves making comparative (e.g., more than, less than, etc.) or evaluative (e.g., better than, worse than, etc.) judgments between RCUs or across RCUs over time.

- Integration (INT) -- refers to the degree to which an MIR contains primary or secondary elaboration that describes the relations between RCUs in an effort to identify links or connections between them; unify; or join or unite them with each other. 
4. RDA Identity Dimensions of Emerging Adulthood-Qualitative Extension (IDEA-QE) Decision Tree Chart (DTC)

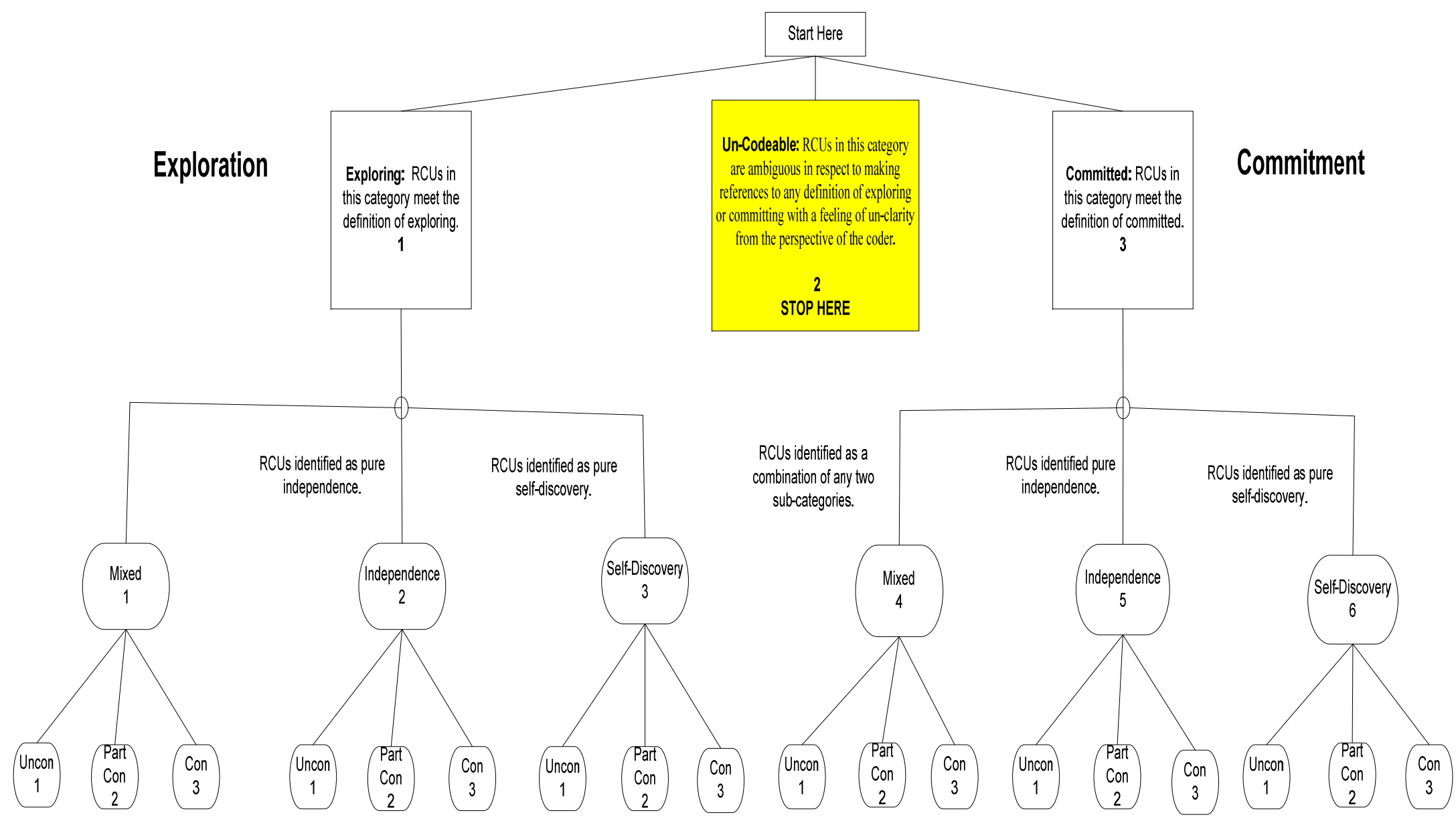

